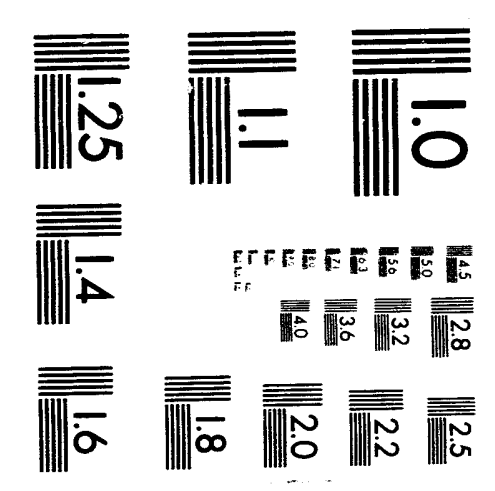



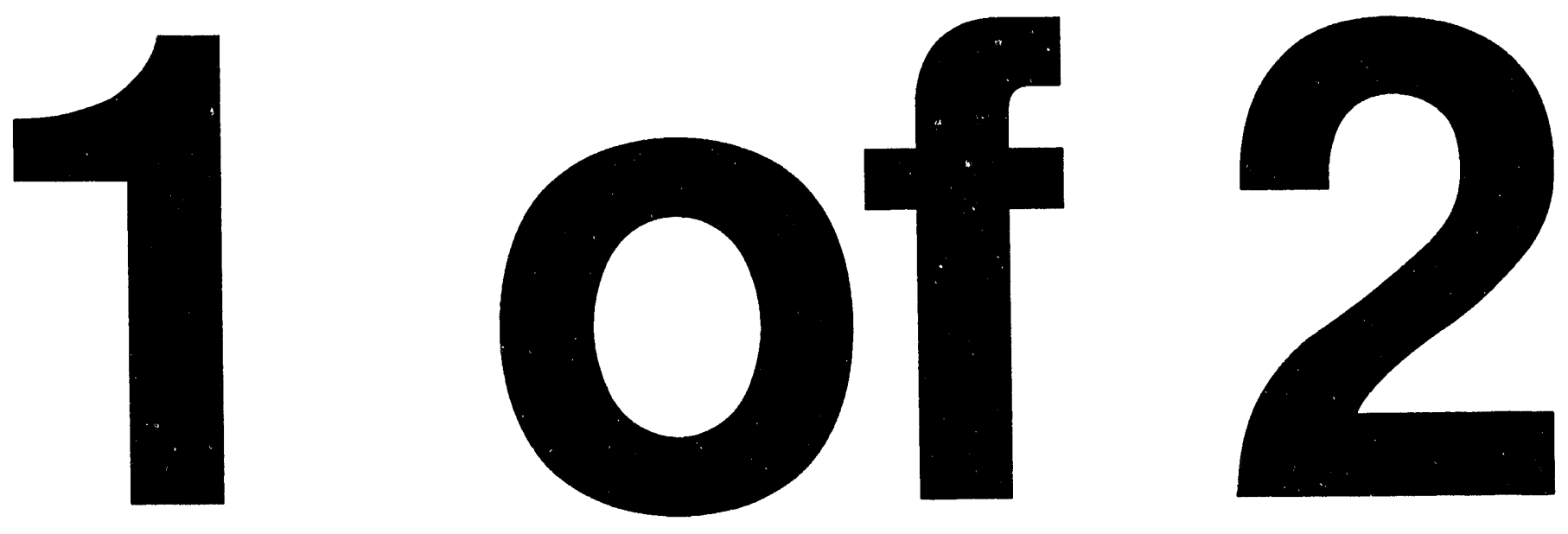


\title{
MULTICRITERIA DECISION METHODOLOGY FOR SELECTING TECHNICAL ALTERNATIVES IN THE MIXED WASTE INTEGRATED PROGRAM
}

\author{
J. J. Ferrada \\ J. B. Berry
}

Manuscript Completed: November 1993

Prepared for the

Mixed Waste Integrated Program

Office of Technology Development

U.S. Department of Energy

\author{
Prepared by the \\ OAK RIDGE NATIONAL LABORATORY \\ Oak Ridge, Tennessee 37831 \\ managed by \\ MARTIN MARIETTA ENERGY SYSTEMS, INC. \\ for the \\ U.S. DEPARTMENT OF ENERGY \\ under contract DE-AC05-84OR21400
}




\section{CONTENTS}

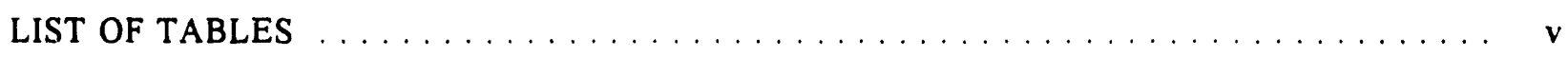

LIST OF FIGURES $\ldots \ldots \ldots \ldots \ldots \ldots \ldots \ldots \ldots \ldots \ldots \ldots \ldots \ldots \ldots$

LIST OF ACRONYMS $\ldots \ldots \ldots \ldots \ldots \ldots \ldots \ldots \ldots \ldots \ldots \ldots \ldots \ldots$ vii

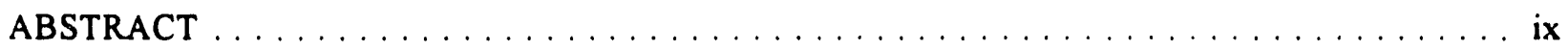

1. INTRODUCTION $\ldots \ldots \ldots \ldots \ldots \ldots \ldots \ldots \ldots \ldots \ldots \ldots \ldots \ldots \ldots$

2. MULTICRITERIA DECISION METHODOLOGIES $\ldots \ldots \ldots \ldots \ldots \ldots \ldots \ldots \ldots$

2.1 INEL PERFORMANCE-BASED TECHNOLOGY SELECTION FILTER APPLICATION 3

2.2 LANL MULTIATTRIBUTE TECHNOLOGY EVALUATION $\ldots \ldots \ldots \ldots \ldots \ldots \ldots \ldots$

2.2.1 Prescreening Methodology $\ldots \ldots \ldots \ldots \ldots \ldots \ldots \ldots \ldots \ldots \ldots$

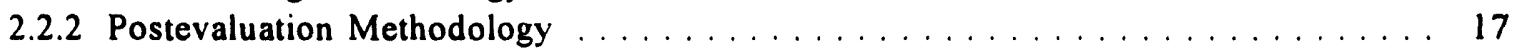

2.3 FUZZY-SET METHODOLOGIES IN MULTICRITERIA ANALYSIS $\ldots \ldots \ldots \ldots \ldots .28$

2.4 ORNL CRITERIA FOR ASSESSING PROCESS TECHNOLOGY OPTIONS $\ldots \ldots \ldots 33$

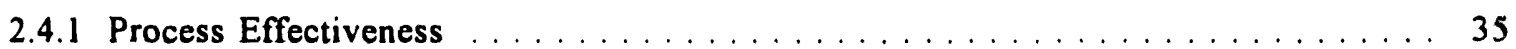

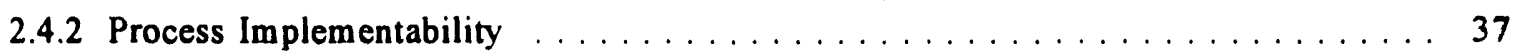

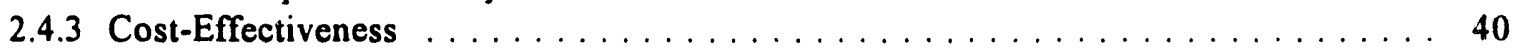

2.5 DECISION-METHODOLOGY EFFORT BETWEEN FEDERAL AGENCIES AND THE

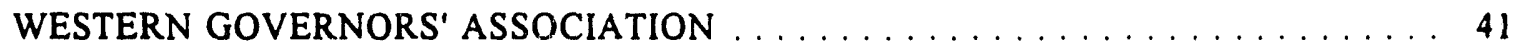

2.6 EVALUATION METHODOLOGY DEVELOPED AT THE PACIFIC NORTHWEST

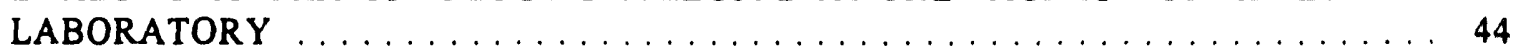

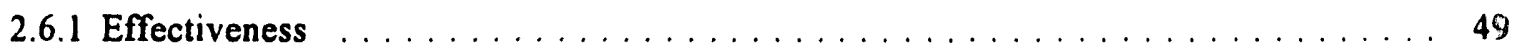

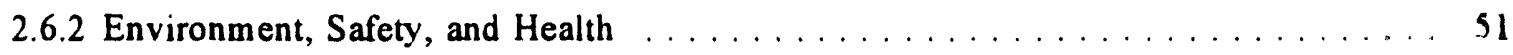

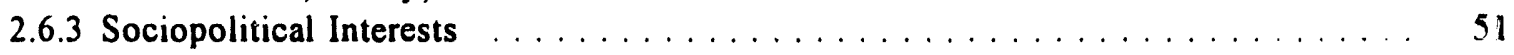

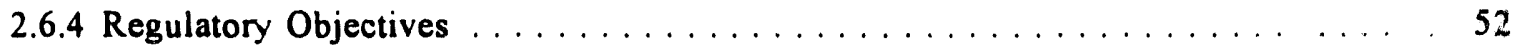

3. CONSIDERATIONS IN SELECTING A DECISION METHODOLOGY . . . . . . . . 5 s

3.1 DECISION CRITERIA SUGGESTED BY THE TECHNICAL SUPPORT GRL TS _ . 3.?

3.1.1 Chemical/Physical Treatment System Technical Support Group . . . . . . . . . . 33

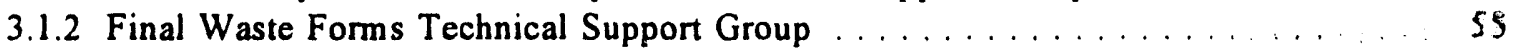

3.1.3 Waste Destruction and Stabilization Technical Support Group . . . . . . . . 57

3.1.4 Second-Stage Destruction and Off-Gas Treatment Technical Support Siroup ... 59

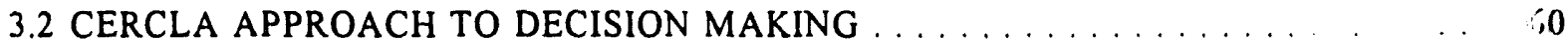

4. DECISION METHODOLOGY RECOMMENDED IN THIS REPORT $\ldots \ldots \ldots \ldots \ldots \ldots$

4.1 DETERMINATION OF SELECTION CRITERIA ELEMENTS $\ldots \ldots \ldots \ldots \ldots$

4.2 EVALUATION OF DECISION CRITERIA ELEMENTS AND AGGREGATION

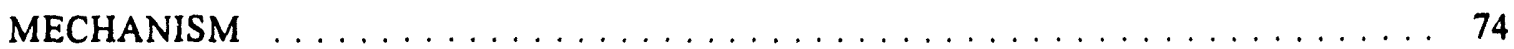




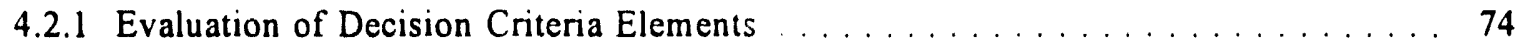

4.2.2 Evaluation of Decision-Criteria-Elements Aggregation Mechanism . . . . . . . 83

4.2.3 Mechanism To Obtain Consensus on Criteria Elements, Evaluation, and Aggregation Mechanism .

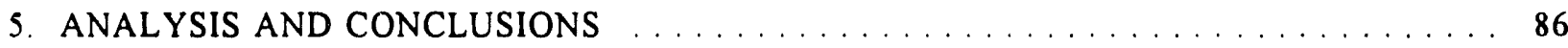

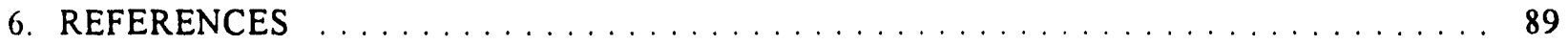




\section{LIST OF TABLES}

Table

Page No.

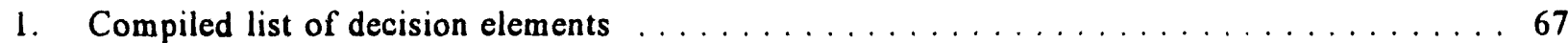

2. Criteria used to evaluate process effectiveness $\ldots \ldots \ldots \ldots \ldots \ldots \ldots \ldots \ldots$

3. Reliability, availability, and maintainability criteria contributing to process

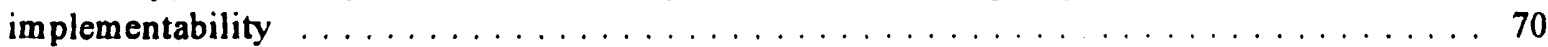

4. Criteria to evaluate regulatory aspects $\ldots \ldots \ldots \ldots \ldots \ldots \ldots \ldots \ldots \ldots \ldots \ldots \ldots$

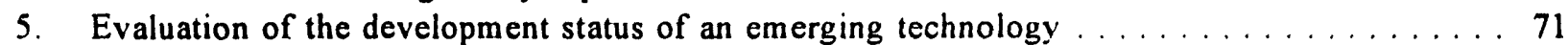

6. Evaluation criteria identifying environment, health, and safety concerns $\ldots \ldots \ldots \ldots \ldots 72$

7. Criteria used to evaluate process cost $\ldots \ldots \ldots \ldots \ldots \ldots \ldots \ldots \ldots \ldots$

\section{LIST OF FIGURES}

Figure

Page No.

1. General methodology to filter technologies $\ldots \ldots \ldots \ldots \ldots \ldots \ldots \ldots \ldots$

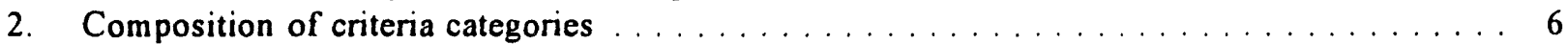

3. Logical steps for fuzzy-set methodology approach $\ldots \ldots \ldots \ldots \ldots \ldots \ldots \ldots$

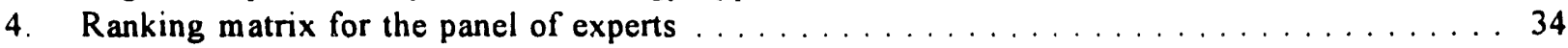




\section{LIST OF ACRONYMS}

$\begin{array}{ll}\text { ARARs } & \text { Applicable or Relevant and Appropriate Requirements } \\ \text { BWID } & \text { Buried Waste Integrated Demonstration } \\ \text { CERCLA } & \text { Comprehensive Environmental Response Compensation and Liability Act } \\ \text { CFR } & \text { Code of Federal Regulations } \\ \text { COTs } & \text { Commercial Off-the-shelf Technologies } \\ \text { D\&D } & \text { Decontamination and Decommissioning } \\ \text { DOE } & \text { U.S. Department of Energy } \\ \text { DOIT } & \text { Developing On-Site Innovative Technologies } \\ \text { ES\&H } & \text { Environment, Safety, and Health } \\ \text { FFCA } & \text { Federal Facility Compliance Agreements } \\ \text { INEL } & \text { Idaho National Engineering Laboratory } \\ \text { LANL } & \text { Los Alamos National Laboratory } \\ \text { LDR } & \text { Land Disposal Restriction } \\ \text { MOU } & \text { Memorandum of Understanding } \\ \text { MWIP } & \text { Mixed Waste Integrated Program } \\ \text { MWTP } & \text { Mixed Waste Treatment Project } \\ \text { NEPA } & \text { National Environmental Policy Act } \\ \text { NMLLWP } & \text { National Mixed Low-Level Waste Program } \\ \text { ORNL } & \text { Oak Ridge National Laboratory } \\ \text { OTD } & \text { Office of Technology Development } \\ \text { PNL } & \text { Pacific Northwest Laboratory } \\ \text { RWMC } & \text { Radioactive Waste Management Complex } \\ \text { SDA } & \text { Subsurface Disposal Area } \\ \text { TASRs } & \text { Technical Area Status Reports } \\ \text { TCLP } & \text { Toxicity Characteristics Leaching Procedure } \\ \text { TRU } & \text { Transuranic } \\ \text { TSG } & \text { Technical Support Group } \\ \text { TTP } & \text { Technical Task Plans } \\ \text { VOCs } & \text { Volatile Organic Compounds }\end{array}$




\begin{abstract}
A BSTRACT
The U.S. Department of Energy (DOE) Mixed Waste Integrated Program (MWIP) has as one of its tasks the identification of a decision methodology and key decision criteria for the selection methodology. The aim of a multicriteria analysis is to provide an instrument for a systematic evaluation of distinct alternative projects. Determination of this methodology will clarify (1) the factors used to evaluate these alternatives, (2) the evaluator's view of the importance of the factors, and (3) the relative value of each alternative. The selected methodology must consider the Comprehensive Environmental Response Compensation and Liability Act (CERCLA) decision-making criteria for application to the analysis technology subsystems developed by the DOE Office of Technology Development.
\end{abstract}

This report contains a compilation of several decision methodologies developed in various national laboratories, institutions, and universities. The purpose of these methodologies may vary, but the core of the decision attributes are very similar. Six approaches were briefly analyzed; from these six, in addition to recommendations made by the MWIP technical support group leaders and CERCLA, the final decision methodology was extracted. Descriptions of these methodologies included (1) a performance-based selection filter developed by Idaho National Engineering Laboratory, (2) a multiattribute technology evaluation developed by Los Alamos National Laboratory, (3) a fuzzy set multicriteria methodology that has been applied to environmental problems, (4) a decision methodology suggested for application at Oak Ridge National Laboratory, (5) a decision methodology developed between federal agencies and the Western Governors' Association, and (6) a decision methodology developed and applied by the Pacific Northwest Laboratory.

Slight variations are observed in the many methodologies developed by different groups, but most of the analyzed methodologies address similar aspects for the most part. These common aspects were the core of the methodology suggested in this report for use within MWIP for the selection of technologies. The set of criteria compiled and developed for this report have been grouped in five categories: (1) process effectiveness, (2) developmental status, (3) life-cycle cost, (4) implementability, and (5) regulatory compliance.

It has been recommended in meetings involving MWIP and DOE-EM-30 that the decision methodology be applied in two phases. The first phase must involve primarily technical aspects such as the ones included in the categories, process effectiveness, developmental status, life cycle-cost, and implementability. In addition, the first phase should include some elements from the regulatory compliance category such as complying with regulations, meeting discharge requirements and requirements for final waste. Phase one of the methodology must act as a first screening method for selecting treatment processes. Once the first screen delivers a set of treatment technologies based on technical issues, then one can apply the second phase which includes some nontechnical issues such as public acceptance, conditions external to site permits, and others. This general procedure will simplify the selection methodology because technical issues are simpler to evaluate. Once the number of viable technologies have been narrowed, then one can apply the second phase with nontechnical elements that are normally more difficult to evaluate for each technology. 
The selection methodology has to be approved by DOE-Headquarters before it is deployed. This report will be submitted to DOE-HQ for its analysis and implementation. Changes suggested from this review process will be incorporated in the methodology. 


\section{INTRODUCTION}

This report addresses the problem of sclecting mixed waste management technologies from a suite of alternatives. In general terms, once the alternative technologics are obtained. a ranking procedure should follow, indicating an order of preference by which the decision maker should establish his/her final decision. It is well known that mixed waste management is a multicritcria decision problem Multicriteria analysis is based on the premise that outcomes of the various decision criteria need not necessarily be transformed into monetary units in order to arrive at a comprehensive comparison of different project outcomes. Other elements besides the traditional monetary evaluation methods, such as social cost-benefit analysis and costeffectiveness analysis must be taken into account-particularly when public concern is involved in the decision-making process.

The U.S. Department of Energy (DOE) Mixed Waste Integrated Program (MWIP) has as one of its tasks the identification of a decision methodology and key decision criteria for the selection methodology. The aim of a multicriteria analysis is to provide an instrument for a systematic evaluation of distinct alternative projects. Results of this task will clarify (1) the factors used to evaluate these alternatives, (2) the importance of the factors, and (3) the relative value of each alternative. The selected methodology must consider the Comprehensive Environmental Response Compensation and Liability Act (CERCLA) decisionmaking criteria for application to the analysis of technology subsystems developed by the DOE Office of Technology Development (OTD).

During FY 1993, work has been performed to identify the multicriteria decision methodology requested by MWIP. Furthermore, this report presents a compilation of existing methodologies that aim at solving the problem of multicriteria decision analysis in mixed low-level waste processes. The results of this compilation in addition to other sources of information will drive the recommended multicriteria decision methodology to be used by DOE MWIP and other projects.

Based on these objectives, the second section of this report describes a scries of selection methodologies, some of which have been suggested as selection tools for use by national laboratories or have been reported as viable tools for any problem in which multicriteria decision making is involved. Six approaches will 
be briefly analyzed: from these six in addition to recommendations made by the MWIP technical support group (TSG) leaders and CERCLA, the recommended decision methodology will be extracted. Descriptions of these methodologies will include (1) a performance-based selection filter developed by Idaho National Engineering Laboratory (INEL),' (2) a multiattribute technology evaluation developed by Los Alamos National Laboratory (LANL), ${ }^{2}$ (3) a fuzzy-set multicriteria methodology that has been applied to environmental problems, ${ }^{3}$ (4) a decision methodology suggested for application at Oak Ridge National Laboratory (ORNL), ${ }^{4}(5)$ a decision-methodology effort developed between federal agencies and the Western Governors' Association, ${ }^{5}$ and (6) a decision-methodology effort developed and applied by the Pacific Northwest Laboratory (PNL). ${ }^{6}$

Section 3 includes considerations and recommendations about sclection methodologies made by the different MWIP TSG leaders on the respective technical area status reports (TASRs) and CERCLA. The TSG TSARs analyzed were the low-level mixed-waste final form group, the chemical/physical treatment group, the waste destruction and stabilization group, and the off-gas treatment technologies group. Section 4 describes the recommended methodology to MWIP that incorporates elements of the methodologies described in Sect. 2 and the considerations of Sect. 3. The recommended multicriteria decision methodology has been adapted for the specific case of MWIP technology selection. Finally, Sect. 5 provides an analysis of the recommended selection methodology. 


\section{MULTICRITERIA DECISION METHODOLOGIES}

\subsection{INEL PERFORMANCE-BASED TECHNOLOGY SELECTION FILTER APPLICATION}

This methodology was developed based on the mission of the INEL Buried Waste Integrated Demonstration (BWID) Systems Analysis. The mission identifies and evaluate systems for the cradle-to-grave remediation of transuranic (TRU)-contaminated Waste Pits and Trenches located within the Subsurface Disposal Area (SDA) of INEL's Radioactive Waste Management Complex (RWMC). The objectives of the project were

- Direct DOE resources to develop technically sound and cost-effective systems for the complete remediation of DOE buried waste sites.

- Guide the selection and technical justification for the development and demonstration of technologies within the BWID program.

- Identify system technology gaps and define quantitative performance requirements for technologies associated with the remediation of DOE Complex buried wastes.

The methodology developed by INEL provides a formalized selection process wherein technologies and systems are rated and assessments are made based on performance measures and regulaiory and technical requirements. The results are auditable and can be validated with field data.

The basic idea of the selection filter recommended by INEL is illustrated in Fig. I. Essentially, the system requirements are formulated by producing the configuration options, which are translated into a series of technology process options and the viability of each is analyzed. The viable alternatives are then subjected to the trade-off study. Those alternatives with high scores are then considered for technology development. The alternatives with low scores are then modified with innovative technologies for reconsideration of their viability. 


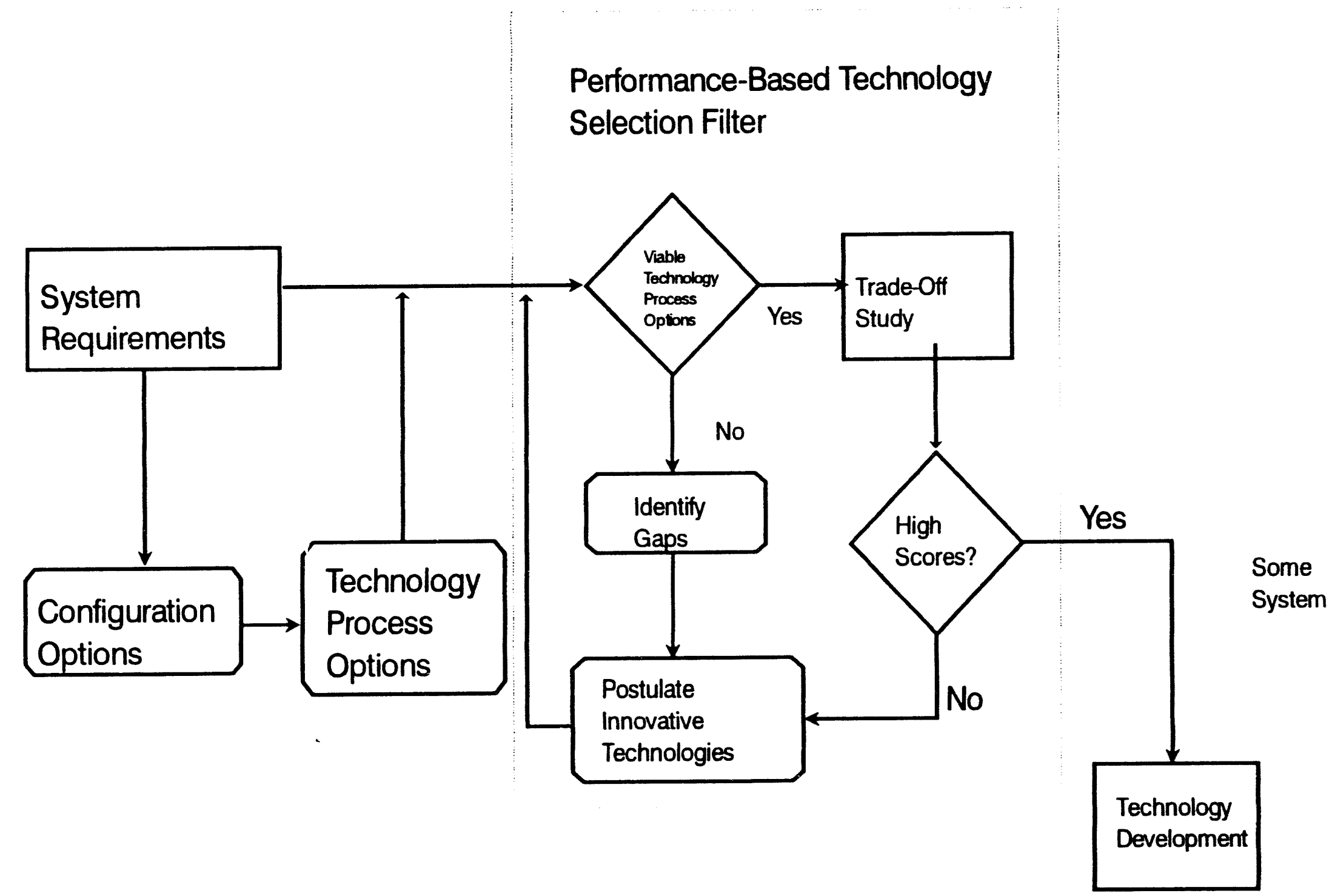

Fig. 1. General methodology to filter technologies. 
The heart of the decision methodology resides in the trade-off studies. INEL has implemented a decision methodology consisting of three areas of analysis: (1) effectiveness, (2) implementability, and (3) cost. Figure 2 illustrates the composition of each of these areas.

Every one of these items is evaluated by means of calculations made with formulas derived from text found in EPA/G-85/003 (Guidance on Feasibility Studies Under CERCLA). Formulas give values between 0 and 1 (represented by the $\mathrm{E}$ values). These formulas are as follows:

1. Volume reduction. This score assesses the ability of the system to reduce waste volume. A measurable way of expressing this is net output volume divided by net input volume:

$$
E_{1}=1-V_{0} / V_{i}
$$

where

$$
\begin{aligned}
& V_{0}=\text { volume of output material from the process, and } \\
& V_{1}=\text { volume of waste matrix. }
\end{aligned}
$$

2. Waste generation. This scores the ability of the system to minimize waste generation. A measurable way of expressing this is the ratio of the volume of contaminated process material to the volume of input:

$$
E_{2}=1-V_{8} / V_{i}
$$

where

$V_{g}=$ volume of contaminated process material produced by the system, and $V_{1}=$ volume of waste matrix. 


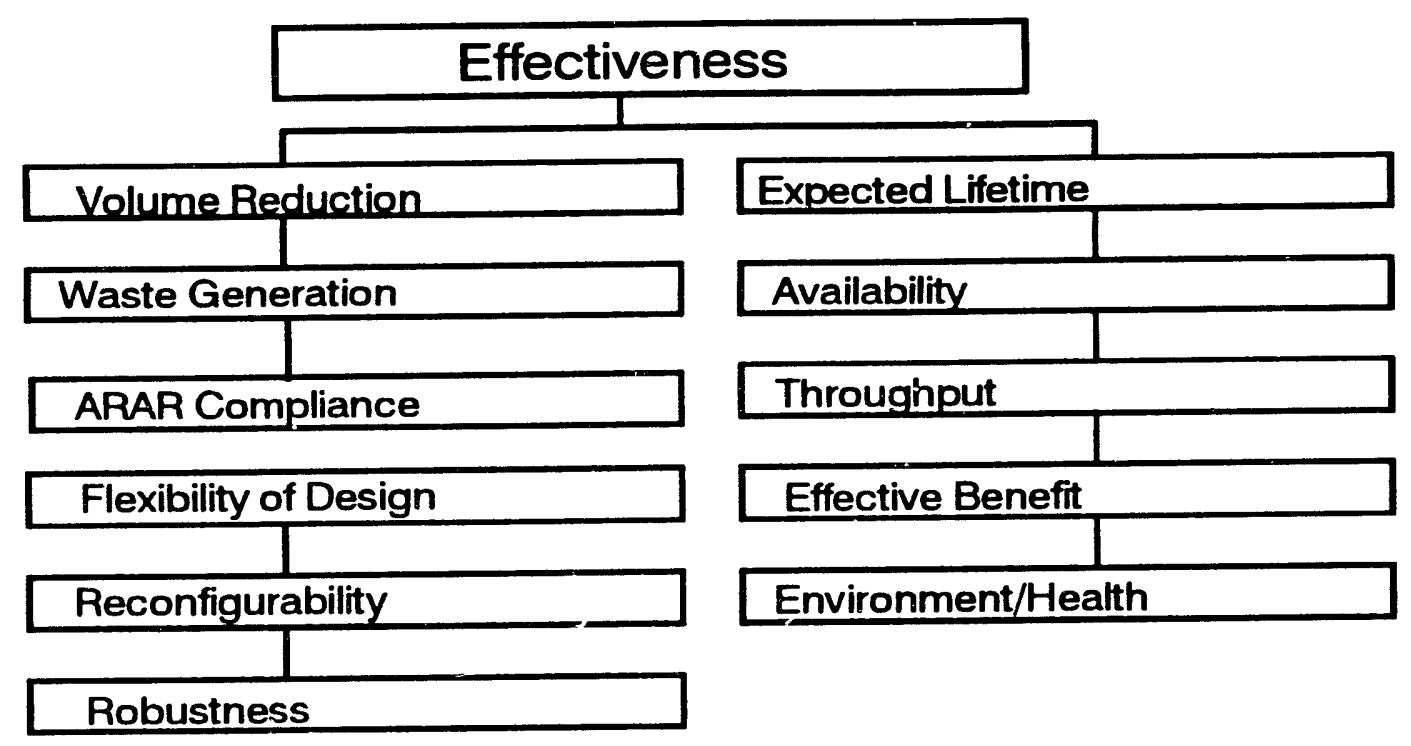

ORNL DWG\#93-15286

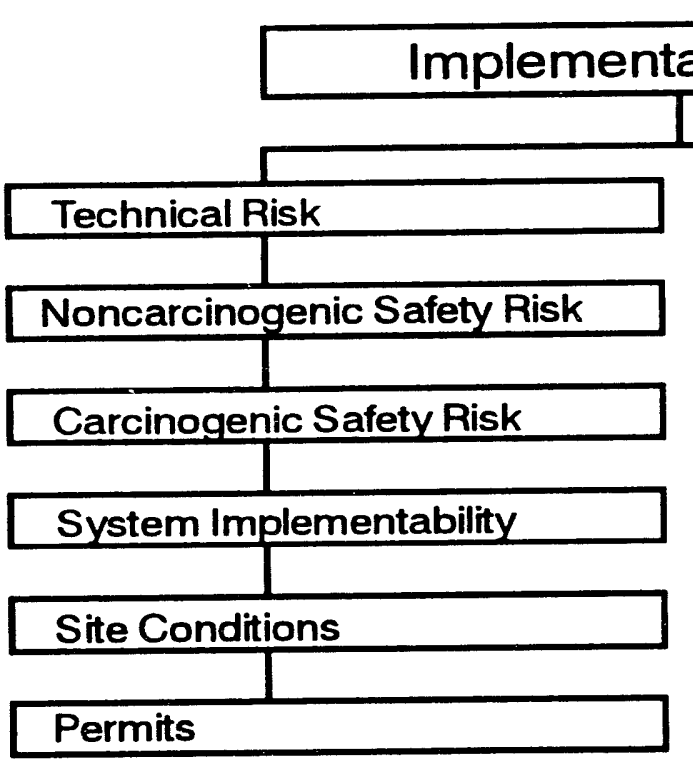

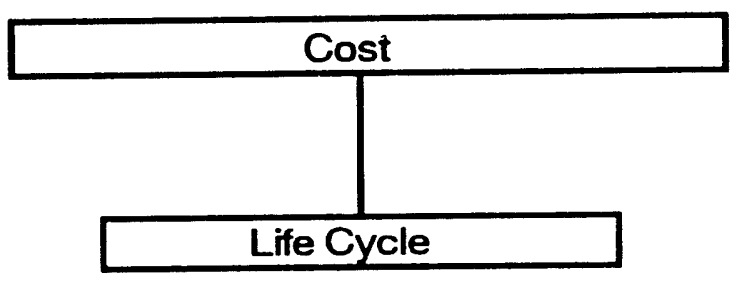

$a$
Fig. 2. Composition of criteria categories.

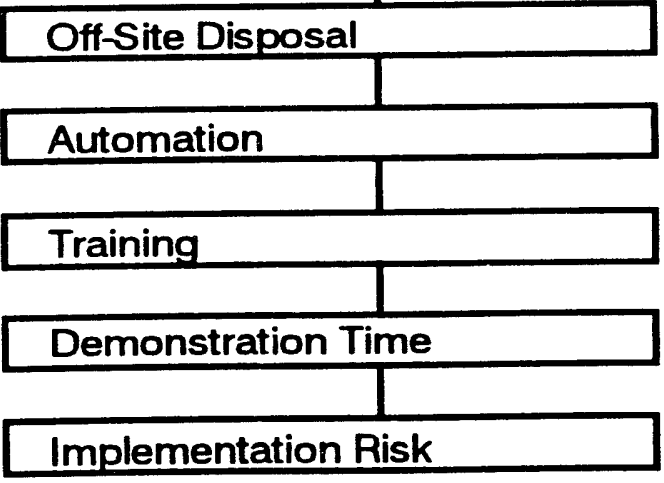


3. Compliance with $A R A R s$. This item is measured as the degree to which process-specific ARARs are satisfied:

$$
E_{3}=E / E_{\max },
$$

where

$E=$ total number of process-specific ARARs satisfied by the technology process option, and

$E_{\text {max }}=$ maximum number of process-specific ARARs associated with any of the initial suite of options being considered.

4. Flexibility of design. This scores assesses the flexibility of the system or subsystems after construction:

$$
E_{4}=F_{s} / F_{t},
$$

where

$$
\begin{aligned}
F_{s}= & \text { number of functional subelements within a configuration option whose requirements } \\
& \text { are satisfied with commercial off-the-shelf technologies (COTs), and } \\
F_{1}= & \text { total number of functional subelements in the configuration option. }
\end{aligned}
$$

5. Reconfigurability. This scores assesses the ability to reconfigure the system or subsystem after construction:

$$
E_{5}=F_{t} / F_{\max },
$$

where

$$
\begin{aligned}
F_{1}= & \text { total number of functional subelements in the configuration option, and } \\
F_{\max }= & \text { number of functional subelements in any of the initial suite of configuration options } \\
& \text { being considered. }
\end{aligned}
$$


6. Robustness. This is a measure of the system's ability to accommodate unanticipated inputs without modification to the system:

$$
E_{6}=N O S / N_{\max },
$$

where

$$
\begin{aligned}
\text { NOS = } & \text { number of predefined out-of-scope inputs (as defined in the input system } \\
& \text { requirements) that the system can remediate, and } \\
N_{\text {max }}= & \text { number of predefined out-of-scope inputs defined in the input system } \\
& \text { requirements. }
\end{aligned}
$$

7. Expected lifetime. This measures the ability of the system to remain operational throughout the remediation process:

$$
E_{7}=T_{l} / T_{r}
$$

where

$$
\begin{aligned}
T_{1}= & \text { time until line-item and capital-equipment replacement costs exceed } 50 \% \text { of } \\
& \text { acquisition costs, and } \\
T_{r}= & \text { time required to remediate } V_{1}
\end{aligned}
$$

8. A vailability. This is measured as the fraction of time during the remediation process that the system is available:

$$
E_{8}=t_{a} / t_{r},
$$

where

$$
\begin{aligned}
& t_{a}=\text { time during the remediation process that the system is available, and } \\
& t_{r}=\text { time duration of the remediation process. }
\end{aligned}
$$


9. Throughput. This parameter measures the time per unit of waste remediated:

$$
E_{9}=K_{s} T_{r} / V_{1}
$$

where

$$
\begin{aligned}
T_{r}= & \text { time to remediate } V_{i}, \text { years, } \\
V_{i}= & \text { volume of waste matrix, } \mathrm{m}^{3}, \text { and } \\
K_{s}= & \text { normalizing site-specific constant used to force this measure between } 0 \text { and } 1, \\
& \mathrm{~m}^{3} / \text { year. }
\end{aligned}
$$

10. Effective benefit. This is measured as the time required to remediate $50 \%$ of the waste.

$$
E_{10}=1-T_{h} / T_{\max }
$$

where

$$
\begin{aligned}
& T_{\mathrm{h}}=\text { time to remediate } 50 \% \text { of the } V_{1} \text {, years, and } \\
& T_{\text {max }}=\text { maximum time (years) allowed for the remediation process. }
\end{aligned}
$$

11. Environment/Public health. This score assesses the ability of the system to maintain a safe environment.

$$
E_{11}=1-C_{i s} / C_{m} \text {, }
$$

where

$$
\begin{aligned}
& C_{i s}=\text { total capital expenses which are important to safety items, and } \\
& C_{m}=\text { total life-cycle cost. }
\end{aligned}
$$

12. Technical risk. This parameter assesses the proportion of the system that has been demonstrated under similar waste and site conditions, plus the proportion of the system that is similar to technology demonstrated under similar waste and site conditions: 


$$
I_{1}=\left(C_{d}+C_{s}\right) / F_{d},
$$

where

$$
\begin{aligned}
C_{d}= & \text { number of subelements in a configuration option whose requirements are } \\
& \text { satisfied with technologies that have been demonstrated under similar site and } \\
& \text { waste conditions, } \\
C_{s}= & \text { number of subelements in a configuration option whose requirements are } \\
& \text { satisfied with technologies which are similar to technologies demonstrated } \\
& \text { under similar site and waste conditions, and } \\
F_{t}= & \text { total number of functional subelements in a configuration option. }
\end{aligned}
$$

13. Noncarcinogenic safety risk. This parameter assesses the ability of the system to maintain a safe environment:

$$
I_{2}=1-R_{p} / R_{n p},
$$

where

$$
\begin{aligned}
& R_{p}=\text { hazard index with the process, and } \\
& R_{n p}=\text { hazard index without the process. }
\end{aligned}
$$

14. Carcinogenic safety risk. This score assesses the ability of the system to maintain a safe environment:

$$
I_{3}=1-R_{p c} / R_{n p c}
$$

where

$$
\begin{aligned}
& R_{p c}=\text { cancer incidence }(\times 1 \mathrm{E}-6) \text { with the process, and } \\
& R_{n p c}=\text { cancer incidence }(\times 1 \mathrm{E}-6) \text { without the process. }
\end{aligned}
$$


15. System implementability. This score assesses the demonstrability of the system:

$$
I_{4}=1-C_{n} / F_{t},
$$

where

$$
\begin{aligned}
C_{n}= & \text { number of subelements in the configuration option whose requirements are } \\
& \text { satisfied with technologies that cannot be demonstrated prior to full-scale } \\
& \text { implementation, and } \\
F_{t}= & \text { total number of functional subelements in the configuration option. }
\end{aligned}
$$

16. Site conditions. This score assesses the site conditions (is based on the ratio of number of subelements previously fielded and operated in a similar environment to the number of subelements in the system):

$$
I_{s}=\left(C_{d}+C_{s}\right) / F_{t},
$$

where

$$
\begin{aligned}
C_{d}= & \text { number of functional subelements in a configuration option whose } \\
& \text { requirements are satisfied with technologies that have been demonstrated } \\
& \text { under similar site and waste conditions, } \\
C_{s}= & \text { number of functional subelements in a configuration option whose } \\
& \text { requirements are satisfied with technologies which are similar to technologies } \\
& \text { demonstrated under similar site and waste conditions, and } \\
F_{1}= & \text { total number of functional subelements in a configuration option. }
\end{aligned}
$$

17. Conditions extermal to site-permits. This score assesses the number of permits required to perform remediation activities:

$$
I_{6}=1 / N_{p} \text {, }
$$


where

$N_{\mathrm{p}}=$ estimated gross number of permits required to perform remediation.

18. Off-site disposal. This parameter assesses the fraction of waste that cannot be moved to offsite disposal:

$$
I_{7}=1-W_{n o} / V_{l}
$$

where

$$
\begin{aligned}
& W_{n o}=\text { volume of waste that cannot be moved to off site disposal, and } \\
& V_{1}=\text { volume of waste matrix. }
\end{aligned}
$$

19. Complexity of operations-automation. This parameter estimates the level of automation:

$$
I_{8}=O / L
$$

where

$O=$ number of hours of operations required for the remediation, and

$L=$ total labor hours required to operate the remediation system.

20. Complexity of operations-training. This parameter assesses the mean number of years of specialized training required to operate the system:

$$
I_{9}=1-Y_{e d} / Y_{\max },
$$

where

$$
\begin{aligned}
Y_{\text {ed }}= & \text { mean number of years of specialized training required to operate the } \\
& \text { remediation system, and } \\
Y_{\text {max }}= & \text { maximum mean number of years of specialized training among the initial set } \\
& \text { of options considered. }
\end{aligned}
$$


21. Time to demonstrate. This parameter assesses the critical path time from initiation of design to initial operation at demonstration:

$$
I_{10}=1-T_{d} / T_{\max },
$$

where

$T_{d}=$ time required until the system can be demonstrated, years, and

$T_{\text {max }}=$ maximum time allowed for remediation process, years.

22. Implementation risk. This parameter assesses the scheduled time from evaluation of design to beginning of operations:

$$
I_{11}=1-T_{b r} T_{\max } \text {, }
$$

where

$$
\begin{aligned}
T_{b r}= & \text { time (years) it takes to build and begin operation of the remediation system, } \\
& \text { and } \\
T_{\text {max }}= & \text { maximum time (years) allowed for the remediation process. }
\end{aligned}
$$

23. Life-cycle cost. This parameter assesses tie cost per unit of waste remediated.

$$
C_{1}=1-C_{m} / C_{\text {max }},
$$

where

$$
\begin{aligned}
& C_{m}=\text { life-cycle cost, and } \\
& C_{\text {mmax }}=\text { maximum life-cycle cost of all processes initially considered. }
\end{aligned}
$$

In order to rank the alternatives using these parameters, an aggregation procedure must follow. The aggregation procedure is explained in Sect. 4.2.2. 


\subsection{LANL MULTIATTRIBUTE TECHNOLOGY EVALUATION}

LANL has developed a multiattribute technology evaluation methodology that has been presented for consideration for DOE programs such as the Mixed Waste Treatment Project (MWTP). ${ }^{2}$ The Office of Operations of Waste Management (OWM) has established the MWTP to implement treatment of mixed low-level waste. The OTD has established the MWIP to address the lack of mixed-waste treatment technologies, treatment capacity, and disposal criteria. The MWIP has established TSGs that focus on specific areas of technical need (e.g., front-end waste handling, chemical/physical treatment, waste destruction and stabilization, off-gas technology, and final waste form).

A simplified, integrated view of the previous efforts is that they are all concerned with identifying new technologies and developing those that show the most promise. This goal is to be accomplished at several "integrated demonstration" sites that have a mix of waste streams representative of a significant portion of the waste streams found throughout DOE. The purpose of an integrated demonstration is to make it convenient and economical to test promising technologies.

Thus, it becomes the responsibility of national programs (MWIP and MWTP) and the entities within the national programs (TSGs) to choose those technologies to be demonstrated and then to select those for further development. These selection functions are the concern of this report. Selection could be carried out by a single person based on one or two subjective criteria. However, a more desirable approach would be to obtain a group-consensus selection based upon a methodical consideration of all the relevant criteria. The LANL multiattribute technology evaluation defines two methodologies: prescreening and postevaluation methodologies. 


\subsubsection{Prescreening Methodology}

The prescreening methodology is a preliminary selection to determine which technologies should be demonstrated. It is used when funding restriction is an issue and when there are more technologies than funding permits testing. This methodology recommends a list of the following six criteria:

- implementability,

- effectiveness,

- applicability (versatility),

- compliance (or acceptability),

- cost, and

- leverage (or resources sharing).

Implementability. This parameter gives high scores to technologies that can likely maintain short schedules (demonstration, pilot, and production); that exhibit high levels of maturity, development and availability; and that are simple, rugged, and easy to maintain.

Effectiveness. This parameter gives high scores to technologies that can easily scale to a high throughput and that have high destruction efficiencies, high waste retrieval rates, large volume reductions, and low consumption of consumables.

A pplicability. This parameter gives high scores to technologies that can treat the most urgent needs and the greatest number of waste streams, that can treat wastes out of compliance, and that can treat wastes that change composition and volume.

Compliance. This parameter gives high scores to technologies that exhibit the highest regulatory compliance, that are most easily permitted, that display the most thorough monitoring, that show the least risk, and that produce the most desirable waste form. 
Cost. This parameter gives high scores to technologies that are most cost-effective, that have the lowest life-cycle costs, and that reduce production costs.

Leverage. This parameter gives high scores to technologies that are new and innovative, that are not currently being funded, and that exhibit private-sector or other-party interest.

Scoring the criteria is accomplished by first mentally ranking the competing technologies according to the perception of their ability to meet the described constituents of the criterion. Then ranking is divided into high, medium, and low ranges. Each technology is given a numerical score of 3, 2 , or 1 , respectively. This methodology will have relevance in most prescreening evaluations. The criteria factors need to be weighted. LANL suggests the following weighting factors:

- I.splementability

$$
\begin{array}{ll}
= & 0.25 \\
= & 0.25 \\
= & 0.25 \\
= & 0.1 \\
= & 0.1 \\
= & 0.05
\end{array}
$$

- Effectiveness

- Compliance

- Cost

- Leverage

The total score is given by

$$
T_{\text {score }}=\sum(W i \cdot S i),
$$

where

$$
\begin{aligned}
& W_{1}=\text { the respective weighting factor, } \\
& S_{1}=\quad \text { the assigned numerical score. }
\end{aligned}
$$

The alternatives are then ranked according to a decreasing score. 


\subsubsection{Postevaluation Methodology}

This variation of the methodology suggests that, after a technology has been demonstrated, enough knowledge will be available to make a more objective evaluation. The methodology is based on the following list of categories and subcategories:

- effectiveness

- contamination control,

- destruction and removal efficiency (DRE),

- volume reduction, and

- final waste form;

- applicability

- scaleability,

- priority waste streams, and

- robustness;

- implementability

- simplicity,

- level of development and availability,

- permitability, and

- off-site disposal;

- cost: life-cycle unit cost;

- acceptability

- public acceptance,

- regulatory compliance, and

- safety risk; and 
- operability

- maintainability,

- availability,

- automation, and

- training.

These subcategories can be evaluated in either of two ways (formulas or figures-of-merits). In some cases the parameter can be calculated by means of a formula or by assigning a score based on appropriate values for the parameter. The subcategories are defined as follows:

1. Contamination control. This criterion assesses the ability of a technology to control the spread of radioactive and hazardous contaminants. The scores for this parameter start with a value of 8. Deductions are made as follows:

2 if there is particulate carryover.,

2 if there is metal volatilization $\left(>2000^{\circ} \mathrm{F}\right)$,

2 if there is $\mathrm{NO}_{x}$ formation, and

2 if secondary discharge treatment is required.

2. Destruction and removal efficiency. This criterion assesses the ability of the technology to remove unwanted contaminants from the waste stream:

$$
S=10 \cdot D R E,
$$

The alternative judgmental scoring gives

$S=10$ if all contaminants are likely to be removed to regulation standards,

$S=5$ if only target contaminants are removed to regulation standards, and

$S=0$ if additional treatment is required to meet regulation standards. 
3. Volume reduction. This criterion assesses the ability of the technology to reduce the original waste form:

$$
S=10 \cdot\left[1-\left(V_{f} / V_{l}\right)\right]
$$

where

$$
\begin{aligned}
& V_{f}=\text { final volume of waste, } \mathrm{m}^{3}, \text { and } \\
& V_{i}=\text { initial volume of waste, } \mathrm{m}^{3} .
\end{aligned}
$$

The alternative judgmental scoring gives

$$
\begin{aligned}
& S \quad=8 \text { if an above-average reduction of waste volume, } \\
& S \quad=5 \text { if an average reduction of waste volume, } \\
& S \quad=2 \text { if a below-average reduction of waste volume, and } \\
& S \quad=0 \text { if the technology increases the volume of waste. }
\end{aligned}
$$

4. Final waste form. This criterion is a measure of the long-term stability of the technology's least stable final waste form:

$$
S=10 \cdot\left(L-L_{\min }\right) /\left(L_{\max }-L_{\min }\right),
$$

where

$$
L_{\min }=\text { stable lifetime of glass, }
$$

$\mathrm{L}_{\max }=$ stable lifetime required by land disposal restrictions (LDRs), and

$L \quad=$ estimated stable lifetime of this technology's least stable final waste form.

The alternative judgmental scoring gives

$S=8$ if the final waste form is glass, rock, or better; 
$S=5$ if the final waste form is better than cement; and

$S \quad=2$ if the final waste form just meets minimum LDR requirements.

5. Scaleability. This criterion assesses the ability of a technology to lower per-unit processing costs by utilizing larger plants to treat larger waste streams. If the capital cost can be expressed proportional to a volumetric flow rate raised to an exponent $\left(C \propto Q^{\mathrm{EXP}}\right)$, then

$$
S=10 \cdot(1-E X P) \text {. }
$$

The alternative judgmental scoring gives

$S=8$ if doubling the processing capacity increases the capital less than $50 \%$,

$S \quad=5$ if large waste streams are sought to make the technology economically attractive, and

$S \quad=2$ if increased capacity can be obtained only by adding more units or if scaling estimates are not provided.

6. Priority waste stream. This criterion assesses the ability of a technology to treat the most important waste streams:

$$
S=10 \cdot \sum\left(T_{i} P_{i}\right) / \sum\left(P_{i}\right),
$$

where

$$
\begin{aligned}
P_{i}= & \text { the relative importance of waste stream } i, \text { and } \\
T_{i}= & \text { the yes/no ( } 1 \text { for yes, } 0 \text { for no) indication of the technology's ability to } \\
& \text { treat waste stream } i .
\end{aligned}
$$

7. Robustness. This criterion measures the ability of a technology to accommodate the expected campaign changes and daily variations as well as unanticipated spikes in the waste stream rate and composition:

$$
S=10 \cdot(1-D E / E)
$$


$E=$ the most influential parameter (e.g., energy, consumable, or residence time required per kilogram of waste treated) controlling the treatment of offdesign waste stream input, and

$D E=$ the required change in $E$ to treat the off-design input.

The alternative judgmental scoring gives

$S=8$ if only small inefficiencies are encountered while treating off-design input,

$S=5$ if off-design inputs can be handled by accepting inefficient operation, and

$S=2$ if special precautions (e.g., pretreatment) are taken to avoid off-design inputs.

8. Simplicity. This criterion assesses the simplicity of the system:

$$
S=10 \cdot\left(U_{\max }-U\right) /\left(U_{\max }-U_{\min }\right),
$$

where

$$
\begin{aligned}
& U_{\text {max }}=\text { maximum number of unit operations encountered, } \\
& U_{m i n}=\text { minimum number of unit operations encountered, and } \\
& U \quad=\text { number of unit operations in the current operations. }
\end{aligned}
$$

The alternative judgmental scoring gives

$S=8$ if below average number of unit operations,

$S=5$ if average or normal number of unit operations, and

$S=2$ if above-average number of unit operations. 
9. Level of development and availability. This criterion assesses the maturity and commercial availability of a technology. Fully developed, operational, time-proven, and commercially available technologies present less technical and implementation risk than emerging, unproved technologies. The criterion is assessed as follows:

$$
S=10 \cdot F S_{\text {tested }} / F S_{\text {total }} \text {, }
$$

where

$$
\begin{aligned}
F S_{\text {tested }}= & \text { the number of subelements that have been tested under similar site and } \\
& \text { waste conditions, and } \\
F S_{\text {total }}= & \text { the number of functional subelements in the technology configuration. }
\end{aligned}
$$

The alternative judgmental scoring gives

$$
\begin{aligned}
& S \quad=10 \text { if the technology is ready to use now, } \\
& S \quad=8 \text { if the technology is fully integrated, and proof-of-principle demonstrated } \\
& \quad \text { on another waste stream, } \\
& S \quad=\quad 5 \text { if pilot scale has been demonstrated but not fully integrated, } \\
& S \quad=\quad 2 \text { if bench scale is being demonstrated, and } \\
& S \quad=0 \text { if technology is in conceptual stage. }
\end{aligned}
$$

10. Permitability. This criterion assesses the effort required to permit the technology:

$$
S=10 \cdot\left(E_{\max }-E\right) /\left(E_{\max }-E_{\min }\right),
$$

where

$E_{\min }=$ the effort (e.g., man-days) required to permit the easiest technology,

$E_{\max }=$ the effort required to permit the most difficult technology, and 
$E \quad=$ the effort required to permit this technology.

The alternative judgmental scoring gives

$S \quad=8$ if the system probably requires a below-average permitting effort,

$S \quad=5$ if the system probably requires an average permitting effort,

$S \quad=2$ if the system probably requires an above-average effort.

11. Off-site disposal. This criterion assesses the availability of acceptable off-site disposal sites:

$$
S=10 \cdot V_{s} / V_{d}
$$

where

$$
\begin{aligned}
& V_{d}=\text { the total volume of treated waste targeted for off-site disposal, and } \\
& V_{s}=\text { the volume of that waste that can be immediately shipped. }
\end{aligned}
$$

The alternative judgmental scoring gives

$$
\begin{aligned}
S= & 10 \text { if off-site disposal is not needed or is readily available, } \\
S= & 5 \text { if shipping backlog can be accommodated with current on-site interim } \\
& \text { storage capacity, and } \\
S= & 0 \text { if additional on-site interim storage will be required. }
\end{aligned}
$$

12. Life-cycle unit cost. This criterion assesses the total life-cycle costs associated with treating a unit of waste:

$$
S=10 \cdot(H-C) /(H-L),
$$


where

$L=$ the lowest life-cycle unit cost based on a survey of plausible technologies,

$H=$ the highest life-cycle unit cost, and

$C=$ the life-cycle unit cost of this technology.

The alternative judgmental scoring gives

$S=8$ if the system probably has below-average life cycle unit costs,

$S=5$ if the system probably has average life cycle unit costs, and

$S \quad=2$ if the system probably has above average life-cycle unit costs.

13. Public acceptance. This criterion assesses the local public's relative acceptance of (or opposition to) the technology. For this criterion

$$
\begin{aligned}
& S \quad=8 \text { if all the effluent is captured and transported elsewhere, } \\
& S \quad=6 \text { if physical treatments are used, } \\
& S \quad=4 \text { if chemical and biochemical treatments are used, and } \\
& S \quad=2 \text { if thermal treatments and incineration are employed. }
\end{aligned}
$$

14. Regulatory compliance. This criterion assesses the degree to which process-specific regulations (federal, state, local, etc.) are satisfied:

$$
S=10 \cdot F,
$$

where

$$
F=\text { the fraction of all applicable regulations that are satisfied. }
$$

The alternative judgmental scoring gives 
$S=10$ if all applicable regulations are satisfied,

$S \quad=8$ if additional design or development will satisfy all regulations, and

$S \quad=0$ if one or more regulations will remain unsatisfied or if additional technologies will have to be applied.

15. Safety risk. This criterion assesses the potential of the technology to maintain a safe environment for operators and the general public. The starting score is 10; deductions are made as follows:

2 if high temperatures $\left(>2000^{\circ} \mathrm{F}\right)$ are involved,

2 if high pressures are involved,

2 if dispersible residues are produced,

2 if highly reactive or corrosive mixtures are involved,

1 if high voltages are used, and

1 if the system is very complex.

16. Maintainability. This criterion assesses the man-hours required to maintain the system:

$$
S=10 \cdot\left(M H_{\max }-M H\right) /\left(M H_{\max }-M H_{\min }\right),
$$

where

$$
M H=\sum_{i=1}^{n}\left(T_{i} R_{i}\right)
$$

where

$$
\begin{aligned}
& n=\text { the number of parts in the system, } \\
& T_{1}=\text { the man-hours required to repair or maintain part } i, \text { and } \\
& R_{1}=\text { the reliability of part } i \text { (which is a sum of scheduled and estimated } \\
& \quad \text { unanticipated maintenance events). }
\end{aligned}
$$


The alternative judgmental scoring subtracts the following from 10 :

3 if above-normal number of moving parts.

3 if components are difficult to access,

3 if components' reliability is questionable, and

2 if difficult to maintain in an alpha cell.

17. A vailability. This criterion assesses the fraction of time that a technology is available for operation. Scheduled maintenance downtime and the probability of equipment failures and associated repair times may decrease availability. The criterion is calculated as follows:

$$
S=10 \cdot A,
$$

where

$A=$ the fraction of time the system is predicted to be available.

Alternative judgmental scoring gives

$S=8$ if the technology is simple (has few moving parts) and is easy to repair,

$S=S$ if the technology is average, and

$S=2$ if the technology is complicated (has many moving parts), has fragile components, and is difficult to repair.

18. A utomation. This criterion assesses the ability to operate a technology with the least amount of human attention:

$$
S=10 \cdot\left(1-M H / M H_{\max }\right),
$$

where

$$
\begin{aligned}
M H_{\text {max }}= & \text { the life-cycle man-hour rate needed to operate the most unautomated } \\
& \text { technology of the set, and }
\end{aligned}
$$


$M H \quad=$ the life-cycle man-hour rate required to operate this technology

Alternative judgmental scoring gives

$S \quad=8$ if the system is obviously automated and requires little setup, adjustment, or attention;

$S=5$ if the system is just ordinary in its human operating requirements; and

$S \quad=2$ if the system is temperamental and requires considerable setup, adjustment, and attention to achieve satisfactory operation.

19. Training. This criterion assesses the amount of training required to operate the technology:

$$
S=10 \cdot\left(1-\pi T_{\max }\right)
$$

where

$T_{\text {ma }}=$ the training required to operate the most difficult-to-operate technology, and

$T \quad=$ the training required to operate the present technology.

Alternative judgmental scoring gives

$S \quad=8$ if the technology is relatively easy to learn and operate,

$S=S$ if an average amount of training is required, and

$S \quad=2$ if the technology is relatively difficult to learn and operate.

In order to rank the alternatives using these parameters, an aggregation procedure must follow. The aggregation procedure is explained in Sect. 4.2.2. 


\subsection{FUZZY-SET METHODOLOGIES IN MULTICRITERIA ANALYSIS}

Fuzzy-set methodology was developed to satisfy a need for a multiattribute decision-making process for the selection of treatment technologies in hazardous materials waste management. ${ }^{3}$ The methodology has been published and applied to a problem of technology selection for treating waste produced at a pesticide company.

When resolving problems related to large-scale engineering projects, usually intangible factors such as environmental quality, prevention of loss of life, aesthetics, legal considerations, and social concerns must be entertained. Besides the various qualitative factors, quantitative criteria, which may include monetary costs and benefits, must also be considered. Additionally, often two or more decision-making groups are involved with a specified project, and the viewpoint of all the interested parties must be properly incorporated into any type of analysis.

In order to isolate the set of the more preferable solutions, the decision makers must first rank the different alternatives against factors or criteria which reflect the major objectives of the study. A rating matrix will be developed and represented with the set of alternatives in one axis against the set of factors in the other axis. A group of experts is asked to rank the alternatives in this matrix. They can use a factor of 0 is they consider that the alternative has a high negative impact on the objectives or a factor of 10 if they consider that the alternative has a highly positive impact on the objectives of the study.

A variety of fuzzy-set aggregation operations are available for combining the individual rating matrices into a single overall rating matrix $R$, where $r_{1,}$ is a typical entry in $R$. For pessimistic aggregation across $K$-rating matrices, each $r_{t \prime}$ entry is defined as

$$
\begin{aligned}
r_{y} & =r_{y}^{(1)} \cap r_{1 y}^{(2)} \cap \ldots \cap r_{1 y}^{(\mathcal{K})} \\
& =\min \left(r_{y}^{(1)}, r_{1 y}^{(2)}, \ldots, r_{y}^{\left(K^{\prime}\right)}\right),
\end{aligned}
$$


where $\cap$ is the intersection fuzzy-set operator. Mean aggregation is given by

$$
r_{y}=1 / K \Sigma r_{y}^{(k)}
$$

The characteristics of the particular problem being studied may help to determine which aggregation procedure to use. Pessimistic aggregation attempts to minimize risk and may therefore be helpful in many situations. The best-case viewpoint among the interest group can be obtained by using optimistic aggregation, and for most applications this is not recommended. If it is desirable to reach a decision based upon an average response from the participants, mean aggregation can be use. When there are polarized opinions, the modified pessimistic aggregation may prove to be useful. The modified pessimistic aggregated matrix is defined as the average of the pessimistic and mean aggregated matrices and is consequently determined as

$$
r_{1 j}=1 / 2\left[\left(r_{1 j}^{(1)} \cap r_{1}^{(2)} \cap \ldots \cap r_{1 j}^{(K)}\right)+\left(1 / K \sum r_{1 j}^{\left({ }^{k}\right)}\right)\right]
$$

For the comparison of altematives, different comparison procedures can be used to identify the most preferable alternatives, once an aggregated matrix is obtained. If a factor exists in the aggregated matrix that possesses the same value across all the alternatives, this factor can be removed since it contains no information that can be utilized for comparing alternatives.

A flexible comparison technique is the dominance matrix concept. A typical element, $d_{y}$, of the dominance matrix, $D$, is the number of factors for which the value of alternative $j$ (column vector) dominates or is greater than alternative $i$ (row vector). The dimensionality of $D$ is equal to the number of alternatives under consideration, and dashes are entered for the diagonal elements because these elements have no meaning in the discrimination process. The following dominance matrix illustrates the comparison method. The sum of the $k$ th column indicates the number of times the kth alternative dominates all the others, while the sum of the $k t h$ row represents the number of times the $k$ alternative is dominated by the others. Hence, the more preferable alternatives possess relatively high column sums and low row totals. These two properties can be 
combined into a single measure by subtracting the row sum from the column sum for each alternative. The better alternative will have the higher calculated value:

\section{Alternatives}

$\begin{array}{lccccc}\text { Alternatives } & A_{1} & A_{2} & A_{3} & A_{4} & \text { Row sums } \\ A_{1} & - & 5 & 3 & 4 & 12 \\ A_{2} & 2 & - & 3 & 4 & 9 \\ A_{3} & 4 & 4 & - & 4 & 12 \\ A_{4} & 3 & 3 & 3 & - & 9 \\ \text { Column sums } & 9 & 12 & 9 & 12 & \end{array}$

This table shows that the difference between the column and row are $-3,3,-3$, and 3 for alternatives $A_{1}$ to $A_{4}$, respectively. Consequently, the ranking of alternatives in order of decreasing preference from best to worst is given by $A_{2}, A_{4}, A_{1}, A_{3}$.

For each factor, a given entry in the rating matrix reflects the magnitude of the impact of the criterion upon the corresponding alternative. To ascertain the relative importance for each factor, a weighting vector can be obtained for a given participant. The aggregation concepts applied to the ranking factors can also be applied to the weighting vectors obtained from the $k$ groups. For instance, if $w_{k}$ represents the weighting vector for the $k t h$ group, where $w_{1 k}$ is a typical entry and $w_{1}$ is the mean aggregated weight vector, $W$ is calculated using

$$
w_{1}=1 / K \sum w_{i k}
$$

After choosing suitable aggregation procedures are chosen to aggregate separately the rating matrices and weighing vectors, these elements can be combined to form a weighted aggregated matrix, $V$, which is calculated by using

$$
V=W^{\prime} \cdot R \text {, }
$$

where $W^{\prime}$ is the diagonal matrix of order $M$ with the aggregated weights $w_{1}=1,2,3, \ldots M$ as the diagonal entries, and $R$ is the aggregated rating matrix of dimensions $M \times N$, where $M$ is the number of factors or criteria and $N$ is the number of alternatives considered. To select the better alternatives in a weighted aggregated matrix, $V$, the dominance matrix can be calculated for $V$. 
Figure 3 summarizes the logical steps required in this fuzzy set approach to multicriteria modeling. The opinions of the experts are solicited by some type of survey specifically designed for the problem. Next, the data collected are transformed into rating matrices for each position. By aggregating all the individual rating matrices using a suitable procedure, an overall aggregated rating matrix can be obtained. A suitable comparison technique, such as the dominance matrix concept, can then be used to isolate the most preferable solutions. The robustness of the conclusions reached to specific changes in the modeling procedures can be ascertained by executing an appropriate sensitivity analysis. Different kinds of sensitivity analyses include considering weights, varying the aggregation methods used, entertaining different threshold levels, and any combination thereof. If contradictory conclusions are reached as a consequence of the sensitivity analysis, further information can be collected for the areas that cause the conflicting results.

The attributes and subattributes suggested for this methodology are as follows:

- performance

- waste volume reduction,

- hazard reduction,

- operational safety,

- ease of operation/reliability,

- flexibility,

- risk (technical),

- risk (regulations), and

- nuisance to local community;

- environmental impact

- air quality,

- water quality, and

- land quality; 


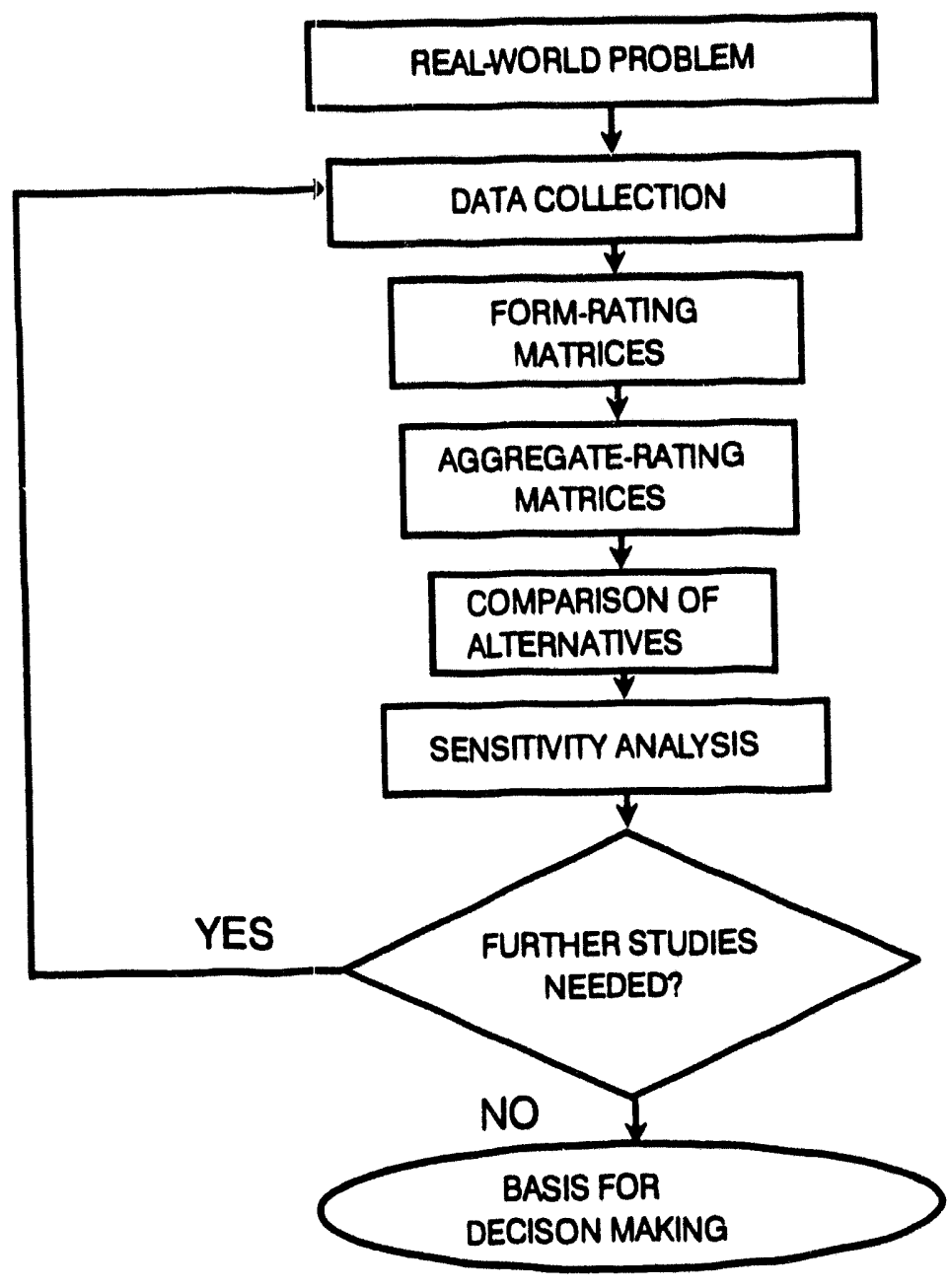

Fig. 3. Logical steps for fuzzy-set methodology approach. 
- social/political

- health of nearby population and/or operators,

- employment,

- political controversy,

- community land value, and

- public acceptance;

- economic aspects

- operational cost, and

- capital cost;

- disposal costs

- transportation of residues,

- landfill,

- long-term exposure,

- surveillance, and

- waste retrieval.

The evaluation of alternatives is conducted by giving the panel of experts a set of matrices (Fig. 4 illustrates one example) that are intended to serve as a format for determining the expert best judgment of the advantages and disadvantages of each alternative. Each matrix contains the alternatives as columns and subattributes as rows. In addition, space is allotted in column 1 next to each subattribute to permit the experts to record their judgment of the weight that should be given to that subattribute.

\subsection{ORNL CRITERIA FOR ASSESSING PROCESS TECHNOLOGY OPTIONS ${ }^{4}$}

In response to the need for a comprehensive and consistent approach to the complex issue of mixed waste management, a generalized methodology for remediation of a mixed waste site was 
ORNL DWG \#93-15288

\begin{tabular}{|c|c|c|c|c|c|}
\hline $\begin{array}{l}\text { Prime ALIbUI } \\
\text { PERFORMANCE }\end{array}$ & Whighming tactor & \multicolumn{4}{|c|}{ Ranking Factor } \\
\hline 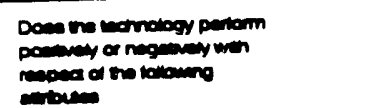 & $\begin{array}{l}\text { Total tor the } \\
\text { prme atribut }\end{array}$ & Alemaine 1 & Alomatwo 2 & Abemative 3 & Alomaine 4 \\
\hline $\begin{array}{l}\text { SUbatmbUin I } \\
\text { WASTE VOLUME } \\
\text { REDUCTON }\end{array}$ & & & & & \\
\hline $\begin{array}{l}\text { SUbatmbutia } 2 \\
\text { HAZARD REDUCTON }\end{array}$ & & & & & \\
\hline $\begin{array}{l}\text { SUbatinbure } 3 \\
\text { OPERATIONAL SAFETY } \\
\text { (wom Operabor standpoint }\end{array}$ & & & & & 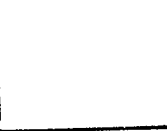 \\
\hline $\begin{array}{l}\text { SUbatmbanta } \\
\text { EASE OF OPERATON } \\
\text { REUNBIUTY }\end{array}$ & & & & & \\
\hline 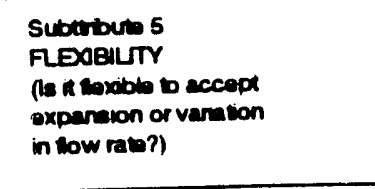 & & & & & \\
\hline 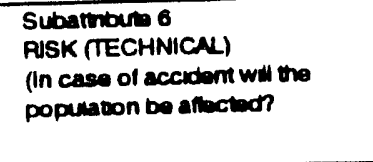 & & & & & 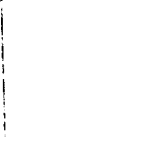 \\
\hline 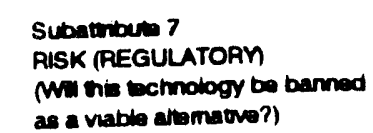 & & & & & \\
\hline
\end{tabular}

Fig. 4. Ranking matrix for the panel of experts. 
developed. ${ }^{4}$ The methodology is based on requirements set forth in CERCLA and in the Resource Conservation and Recovery Act (RCRA) and incorporates "lessons learned" from process design, remediation methodologies, and remediation projects. The methodology was applied to the treatment of 32,000 drums of mixed waste sludge at the Oak Ridge K-25 Site.

Process technology options were developed and evaluated, first with regard to meeting system requirements and then with regard to CERCLA performance criteria. Configuration options were established as a top-level block flow diagram and are assessed by comparison with system requirements. Process technology options were developed to define specific technologies or requirements for each "block" within the "configuration option" flow diagram. Functional and operating requirements were established for each block or functional subelement. Alternatives are further screened against these performance requirements. The result is an engineered system that meets system as well as functional and operating requirements.

The criteria for assessing process technology options were grouped into three broad categories: effectiveness, implementability, and cost. Formulas were developed for each performance criterion to quantitatively evaluate process technology options. Criteria for the "development and screening of alternatives" are discussed in Title 40 of the Code of Federal Regulations (CFR), Part 300.430.

\subsubsection{Process Effectiveness}

The formula and definition for calculating the score for each process options are as follows:

1. Volume reduction. It is calculated as volume reduction of primary waste stream:

$$
\text { Volume reduction }=1-V_{0} / V_{i} \text {, }
$$

where

$$
\begin{aligned}
& V_{0}=\text { volume of output material, and } \\
& V_{1}=\text { volume of waste input stream. }
\end{aligned}
$$


2. Compliance to ARARs. It takes into account releases to the environment as fraction of allowable release:

$$
\text { Compliance }=1-\left(A_{\text {oct }} / A_{\text {allow }}\right) \text {, }
$$

where

$$
\begin{aligned}
& A_{\text {act }}=\text { actual concentration of pollutant of concern, and } \\
& A_{\text {allow }}=\text { allowable concentration of pollutant of concern }
\end{aligned}
$$

3. Secondary waste generation. This criterion takes into consideration the amount of contaminated material as compared with input volume:

$$
\text { Secondary waste }=V_{s} / V_{i} \text {, }
$$

where

$$
\begin{aligned}
& V_{s}=\text { volume of secondary waste generated. } \\
& V_{i}=\text { volume of waste input stream. }
\end{aligned}
$$

4. Throughput. Throughput takes into consideration the time required to process per unit of waste remediated:

$$
\text { Throughput }=1-K_{s} \cdot T_{r} / V_{i} \text {, }
$$

where

$$
\begin{aligned}
T_{r}= & \text { time to remediate the waste, years, } \\
V_{1}= & \text { volume of waste input stream, and } \\
K_{s}= & \text { site-specific constant to force the performance measure be between } 0 \text { and } 1, \\
& \mathrm{~m}^{3} / \text { year. }
\end{aligned}
$$


5. Effective benefit. This represents the time required to process $50 \%$ of the waste:

$$
\text { Effective benefit }=1-T_{h} / T_{\max } \text {, }
$$

where

$$
\begin{aligned}
& T_{h}=\text { time to remediate } 50 \% \text { of the waste, years, and } \\
& T_{\text {max }}=\text { maximum time allowed for the remediation process, years. }
\end{aligned}
$$

6. Risk to employees. This estimates the proportional risk to employees with/without process:

$$
\text { Risk to employees }=0.2 R_{n p} / R_{p} \text {, }
$$

where

$$
\begin{aligned}
& R_{n p}=\text { quantified risk without process, and } \\
& R_{p}=\text { quantified risk with process. }
\end{aligned}
$$

7. Environment/public health. This estimates risk to public with/without process:

$$
\text { Environment, public health }=0.2 \cdot M_{c p} / M_{c} \text {, }
$$

where

$$
\begin{aligned}
& M_{c p}=\text { toxic content of processed waste input, and } \\
& M_{c}=\text { potential toxic loss to environment. }
\end{aligned}
$$

\subsubsection{Process Implementability}

The formulas for assessing performance criteria for process implementability are as follows:

1. Permits. This calculates the number of permits required:

$$
\text { Permits }=1 / N_{p} \text {, }
$$


where

$N_{p}=$ number of permits required.

2. Industrial availability. This estimates the ability of the subcontractor to supply required equipment:

$$
\text { Industrial availability }=F_{s} / F_{t} \text {, }
$$

where

$$
\begin{aligned}
& F_{s}=\text { commercial off }- \text { the-shelf functional subelements, } \\
& F_{t}=\text { total functional subelements. }
\end{aligned}
$$

3. Simplicity of design. This calculates the number of functional elements:

$$
\text { Simplicity }=F_{1} \text {. }
$$

4. Robustness. This calculates the ability of the system to process a range of inputs without affecting system operations or product quality:

$$
\text { Robustness }=N_{o k} / N_{0} \text {, }
$$

where

$$
\begin{aligned}
N_{o k}= & \text { number of predefined influent characteristics that do not have significant } \\
& \text { potential to affect system performance, and } \\
N_{0}= & \text { number of predefined influent characteristics the system will be required to } \\
& \text { process. }
\end{aligned}
$$

5. Implementation risk. This criterion calculates the scheduled time from approval of contract to beginning of operation:

$$
\text { Implementation risk }=1-T_{c} / 30,
$$


where

$$
\begin{aligned}
& T_{c}=\text { time to begin remediation after contract award, years, and } \\
& 30=\text { time to complete remediation, years }
\end{aligned}
$$

6. Technical risk. Technical risk estimates the ratio of the number of subelements demonstrated in both actual and similar environments to the total number of subelements:

$$
\text { Technical risk }=\left(C_{d}+0.75 \cdot C_{s}\right) / F_{s},
$$

where

$$
\begin{aligned}
& C_{d}=\text { number of demonstrated subelements, } \\
& C_{s}=\text { number of similar demonstrated subelements, and } \\
& F_{t}=\text { total functional subelements. }
\end{aligned}
$$

7. Demonstrability. This estimates the subelements not demonstrated before full-scale implementation:

$$
\text { Demonstrability }=1-C_{n} / F_{t} \text {, }
$$

where

$$
C_{n}=\text { number of subelements that cannot be demonstrated. }
$$

8. Implementation time. This estimates the time from identification of problem to completion of operations:

$$
\text { Implementation time }=1-T_{i} / T_{\max } \text {, }
$$

where

$$
\begin{aligned}
& T_{1} \quad=\text { time from identification of problem to completion of operations, and } \\
& T_{\max } \quad=\text { time allowed for completion of operations. }
\end{aligned}
$$


9. Future disposal. This criterion estimates the fraction of waste that will be difficult to reprocess:

$$
\text { Future disposal }=1-V_{\text {no }} / V_{0} \text {, }
$$

where

$$
V_{n o} \quad=\text { volume of waste that will be difficult to reprocess. }
$$

\subsubsection{Cost-Effectiveness}

The formulas for assessing performance criteria for process cost-effectiveness are as follows:

1. Implementation cost. This formula estimates the cost per unit volume of waste treated:

$$
\text { Implementation cost }=1-C_{m} / C_{\max } \text {, }
$$

where

$$
\begin{aligned}
C_{m}= & \text { cost of subcontractor or capital and operating cost plus institutional costs } \\
& \text { (e.g., project management, documentation), and } \\
C_{\max }= & \text { maximum lifecycle cost of all processes initially considered. }
\end{aligned}
$$

2. Complexity of operations-automation. This estimates the number of hours per hour of operation.

$$
\text { Complexity-automation }=1-O / L \text {, }
$$

where

$$
\begin{aligned}
& O=\text { operation hours, and } \\
& L=\text { operational labor hours. }
\end{aligned}
$$


3. Complexity of operations-Iraining. This formula estimates the fraction of staff that require specialized training or experience to operate the system:

$$
\text { Complexity-training }=1-S E / S \text {, }
$$

where

$$
\begin{aligned}
& S E=\text { staff requiring specialized training or experience, } \\
& S=\text { total operational staff. }
\end{aligned}
$$

\subsection{DECISION-METHODOLOGY EFFORT BETWEEN FEDERAL AGENCIES AND THE WESTERN GOVERNORS' ASSOCIATION"}

A Memorandum of Understanding (MOU) between federal agencies and the Western Governors' Association has the intent of establishing a more cooperative approach to the development of technical solutions to the environmental restoration and waste management problems shared by the states, commercial entities, and the federal government. To carry out the MOU, a federal advisory group known as the Developing On-Site Innovative Technologies (DOIT) Committee was formed.

A critical element in achieving the goals of the DOIT Initiative is developing criteria to facilitate site selection and technologies. Because selection decisions are fundamental to the success of the initiative, the general working group developing the selection criteria represents a cross section of industry, public interest groups, and federal and state representatives. These criteria and other requirements in the Stakeholder Involvements Plan will be used to request and evaluate proposals for cooperative demonstrations. In general terms, DOIT would include the following criteria categories: needs, public acceptance, technical, cost/benefit, and business management.

Needs. This category includes the following: 
- Responsiveness of the site's proposal to the federal and state needs as defined in the Stakeholder Involvement Plan. Bias should be in favor of action, not study.

- Maturity and character of the problem.

- Overall protection of human health and the environment.

- Schedule requirements.

- Performance requirements.

- Site and problem selection that are representative of

- the geographic region,

- the waste streams present in the region

- site ownership, and

- applicability for use at other sites.

- Demonstrated understanding of the problems and technology requirements.

Public acceptance. This category includes the following:

- Acceptability of the plan and schedules by the stakeholder, particularly regulators.

- Adequacy of stakeholder involvement.

Technical. The technical category includes the following:

- Potential for successful permitting and regulatory acceptance

- Adequacy of technology demonstration including addressing technical uncertainties.

- Adequacy of safety and National Environmental Policy Act (NEPA) requirements beyond those required by permits.

- Likelihood of early success (implementability).

- Short-term effectiveness.

- Long-term effectiveness and permanence.

- Reduction of toxicity, mobility, and volume through treatment.

- Adequacy of test planning and quality assurance approach. 
- Potential for commercialization and use (if successful) by other sites within the western states.

- Compliance with chemical-specific and reniedial action-specific ARARs.

CosvBenefit. Cost/benefit includes several factors as follows:

- Work-force adequacy.

- Approach to cost/benefit analysis of potential technology solution.

- Cost also becomes a consideration to commercial stakeholder in assessing the potential return on investment (i.e., profitability).

- Cost will be considered by each agency funding a specific proposal.

Business Management. This category includes the following:

- Adequacy of proposed management plan.

- Commitment of management (resources, facilities, people, etc.).

- Approach to procurement.

- Experiences of management organization.

Based on these criteria categories, DOIT is considering a selection criteria element list that is currently evolving dynamically that would include among others the following items:

- land disposal restriction compliance;

- pretreatment requirements;

- process complexity;

- technology maturity;

- applicability;

- radioactive contamination control;

- cost; 
- permitability;

- flexibility;

- maintainability;

- safety risk;

- effluent;

- throughput;

- final waste form;

- criticality control;

- support of federal, state, and local government;

- statistical effectiveness of the technology;

- adequate access to contamination;

- geology;

- potential adverse affects to public health and environment;

- cleanup time frame;

- demonstrability;

- robustness;

- permanence of remediation; and

- emission controls.

\subsection{EVALUATION METHOdOLOGY DEVELOPED AT THE PACIFIC NORTHWEST LABORATORY}

PNL has developed Phase I of a three-phased study to support evaluation of new clean up technologies for federal facilities. It directly supports the Volatile Organic Compounds (VOCs)Arid Site Integrated Demonstration being conducted at the Hanford Site. The purpose of the activity, sponsored and directed by DOE's OTD is to develop and demonstrate new technologies for cleaning up carbon tetrachloride and other VOCs in soils and groundwater. Ultimate deployability of these innovative technologies will be the measure of success. Phase $I$ of the 
institutional assessment task focuses on gathering Hanford stakeholder input on how to evaluate technologies. Phase II will involve stakeholders applying the technology evaluation criteria to actual demonstration technologies. In Phase III, the task will evaluate stakeholder acceptability of innovative technologies at other DOE candidate sites. Only if a technology performs effectively during demonstration and is accepted by the regulatory community and the public, can it be recommended for deployment.

Phase I consisted of a series of stakeholder interviews and two stakeholder workshops, both designed to receive input about the criteria to be used to evaluate innovative technologies. Approximately 40 people were interviewed. They included representatives of the following categories:

- Regulatory agencies,

- Federal, state, and local governments,

- Native American tribes,

- Public interest groups,

- Business and labor groups,

- Agriculture,

- Education,

- Industry,

- DOE site contractors, and

- Hanford retirees.

The purpose of the interviews was to obtain stakeholder input on the important factors in evaluating new cleanup technologies. A set of draft technology evaluation criteria served as the basis for discussion. The interviews thus focused on defining evaluation criteria and discussing ways to evaluate their relative importance. As preparation, the team prepared draft technology evaluations to use as a basis for discussion. The discussion was open-ended, thus encouraging wide-ranging input on technology evaluation criteria and values. After the interviews were 
completed, interviewees were given an opportunity to review the results of their interviews and provide additional information if desired.

Then two stakeholder workshops were planned to discuss the revised draft technology evaluation criteria. Discussion groups were formed. Each discussion group was assigned a facilitator. Participants were asked to express their understanding of the draft criteria, to suggest changes or new criteria, and to provide an understanding of what should be considered in evaluating new technologies. Participants also completed a brief exercise designed to evaluate the relative importance of the criteria to each individual.

The background of the people interviewed included a significant level of familiarity with issues of Hanford cleanup. In most cases the individuals interviewed have participated in public outreach activities, regulatory oversight functions, advisory roles, technical activities, or other capacities in relation to the facility.

Based on the results of the workshops as well as on the earlier developmental work of the interviews, a recommended revised set of technology evaluation criteria was developed. The criteria are intended for use in Phase II to test their applicability, usefulness, and ability to evaluate the issues related to regulatory and public acceptability of deployability of different cleanup technologies.

PNL has grouped the evaluation criteria elements in different categories. Effectiveness is one of the primary categories. It includes performance, cost, and time. The elements that comprise the performance criterion include remaining contamination, process waste, practicality, and whether the technology "works" or functions as intended. The criterion for remaining contamination refers to, for example, the $1 \%$ remaining after $99 \%$ effective groundwater treatment technique is completed. The remaining contamination is to be measured according to how much contaminant mobility, volume, and toxicity are reduced by the technology. 
The criterion for process waste refers to waste produced by the technology itself, or the process of its application. The status of the waste can be assessed, including consideration of waste mobility, volume, degree of hazard represented by the character of the waste, and recycle potential. Waste treatment requirements needed to address a given technology's residuals can be assessed, and the availability of the needed treatment technology defined. Requirements for decontamination and decommissioning (D\&D) of a technology and the resulting waste can be evaluated. The technology can also be evaluated according to the need for waste disposal and whether such disposal capacity is available. The nature of available disposal (e.g., landfill versus more progressive disposal method) should also be considered.

Practicality is defined by several criteria. It assesses whether use of a given technology will preclude or foreclose future cleanup options. It evaluates whether a technology is reliable and can be expected to operate with minimal operational problems and production downtime. Versatility of the technology to address other types of contamination in other media or at other locations can also be assessed.

Cost is addressed by this methodology. Two elements that comprise the cost criterion include technology startup cost and operations and maintenance cost.

Time is an important criterion. Time includes the length of time until the technology is available, the speed or rate at which the technology operates, and the total time needed to achieve the given objectives.

Environment, safety, and health (ES\&H) is another category defined in this methodology. This category includes worker safety, public health and safety, and environmental impacts. The criteria for evaluating a technology according to its worker-safety aspects include the level of exposure of workers to hazardous materials or other hazards resulting from use of the technology, the physical requirements of developing and operating the technology, and the number of workers required. 
Public health and safety is intended to refer to all those people who are not workers at the facility. Public health and safety aspects of a given technology can be evaluated based on the number, type, and severity of accidents postulated to occur related to that technology's development, operation, and decommissioning.

Environmental impacts include any effects on the ecology of the remediation site. For example, wildlife, vegetation, air, water, soil, and people, and aesthetic impacts such as visual impacts and noise.

Sociopolitical interest is another category defined by this methodology. Criteria attached to this category include (a) public perceptions of a technology, (b) tribal rights and future land uses associated with technology demonstration and deployment, and (c) socioeconomic interests.

Public perception evaluates the reputation of the proponent of a technology. This may apply to a government agency, a national laboratory, an academic institution, a contractor firm, or a private industry partner. The degree of familiarity of a technology and its use are key factors affecting public perception of a given technology.

Tribal rights and future land uses evaluates the Native American values related to the land offering criteria for evaluating alternative cleanup technologies.

Socioeconomic interests evaluates the effects of a technology or suite of technologies on the economic base of the community, including fiscal as well as less tangible impacts. Impacts may include local infrastructure requirements (e.g., sewer, fire protection, etc.), labor force turnover (if new or different capabilities are needed), housing values, or other factors. Availability of the required labor force can be evaluated for different technologies, including the need for personnel training. 
Regulatory objectives are another category defined by the methodology. It includes compatibility with facility cleanup milestones, regulatory infrastructure and track record, and regulatory compliance.

Compatibility with cleanup milestones evaluates the ability of a technology to support compliance with cleanup milestones and involves assessing its ability to contribute to meeting the regulatory cleanup requirements that have been established for a given site, in a time frame and in compliance with standards that would be applied in any other remediation situation. Regulatory infrastructure/track record evaluates the experience of regulators with a specific technology or a similar technology that may result in the regulators being predisposed to find the technology acceptable. The number and complexity of the regulatory programs that apply to a given technology should be evaluated. Regulatory compliance evaluates the ability of a technology or suite of technologies to achieve regulatory cleanup standards and to maintain an ongoing protection of public and worker health and safety and the environment. Compatibility with state waste management priorities is part of this criterion as is compliance with NEPA. The level of uncertainty associated with regulatory compliance is also a factor that affects the measurement of this criterion.

A summary of the attributes for each category proposed by PNL is listed in Sects. 2.61-2.6.3.

\title{
2.6.1 Effectiveness
}

\author{
PERFORMANCE \\ Remaining Contamination \\ Contaminant Mobility Reduction \\ Contaminant Volume Reduction \\ Contaminant Toxicity Reduction \\ Process Waste \\ Status of Waste
}


Mobility

Volume

Hazard

Recyclability

Treatment

Needed

Available

Decontamination/Decommissioning

Disposal

Needed

Available

Practicality

Foreclose future options

Reliability

Failure control

Ease of use

Infrastructure

Versatility

System compatibility

Off-The-shelf

procurement ease

Maintainability

Safety measures

COST

Start-up cost

Operations and maintenance cost

Life-cycle cost 


\title{
TIME
}

Years until available

Speed/rate

Years to finish

\subsubsection{Environment, Safety, and Health}

\author{
WORKER SAFETY \\ Exposure to hazardous materials/hazards \\ Physical requirements \\ Number of people required \\ PUBLIC HEALTH AND SAFETY \\ Accidents \\ Routine releases \\ Transportation
}

\section{ENVIRONMENTAL IMPACTS}

Ecological impacts

Aesthetics

Natural resources

Energy demands

\subsubsection{Sociopolitical Interests}

\section{PUBLIC PERCEPTION}

Proponent reputation

Familiarity/understandability 
TRIBAL RIGHTS/FUTURE LAND USES

Capacity for unrestricted use

Terrestrial, aquatic

SOCIOECONOMIC INTERESTS

Economic impacts

Labor force demands

\subsubsection{Regulatory Objectives}

A Workshop on Compatibility with Cleanup Milestones, Regulatory Infrastructure/Track Record, and Regulatory Compliance has been proposed as part of the methodology.

Workshop participants and interviewees have recognized the difficulty of developing such a set of measurable, precise criteria at this stage. It is recognized that the set of criteria listed in Sects. 2.6.1-2.6.4 include some that are relatively easy to measure and define.

The usefulness of these criteria will only be demonstrated when they are actually applied to a set of cleanup technologies. This is the objective of Phase II of the institutional assessment task. It was suggested that a series of small working sessions be conducted, bringing in representatives of the stakeholder groups as well as program personnel with technical resource capabilities. The results of the small group sessions during the workshops confirmed that a small, focused group can best grasp and discuss the complex elements of evaluating cleanup technologies. Phase II outreach activities should provide valuable insights into how workable and applicable the criteria are to actual evaluation of new technologies. 


\section{CONSIDERATIONS IN SELECTING A DECISION METHODOLOGY}

Requirements for selecting a decision methodology for technology selection must conform to specific needs within MWIP. These needs have been addressed to some extent in the TASRs provided by the different technical support groups. Almost without exception, every report has pointed to some set of criteria elements that the respective members would like to match their technologies against in order to make an appropriate decision. Section 3.1 describes the specific interest of the different technical support groups in terms of considering criteria elements. Section 3.2 describes some of the CERCLA-suggested decision elements.

\subsection{DECISION CRITERIA SUGGESTED BY THE TECHNICAL SUPPORT GROUPS}

\subsubsection{Chemical/Physical Treatment System Technical Support Group?}

The methodology suggested by the Chemical/Physical Treatment System Technical Support Group to perform trade-off studies and evaluate the proposed equipment and technology is based mainly on the LANL study.' A listing of the decision elements is as follows:

- capital cost-affecting factors

- scale of operation,

- design reliability (safety factors),

- necessity of a pilot plant, and

- number of steps required;

- operation cost-affecting factors

- maintenance costs, 
- energy requirements, and

- separation efficiency and decontamination factor;

- primary pollutant removal

- be able to remove the required species or component,

- meet waste discharge requirements,

- meet the requirements of the final form process to comply with the LDR, and

- meet all regulatory and effluent standards and requirements for permitting;

- secondary waste generation and volume reduction: include ability to entrain the radioactive components into a waste residual that will go to final forms processing rather than to incinerator and potentially end up in the off-gas system;

- safety

- contamination control and

- inherent hazard;

- versatility (i.e., capability to respond to changing requirements);

- experience/maturity (i.e., degree to which the technology can be developed, tested, and made ready for operation);

- simplicity/operability

- smaller number of pretreatment steps and

- reliability and maintainability;

- throughput:

- equipment or system throughput adequate to meet system requirements; 
- acceptability

- regulatory compliance,

- easily permitted, and

- community acceptance.

In addition, the Chemical/Physical Technical Support Group, using the previous elements as a basis, has developed a sort of data base of technologies in which the elements to check for the demonstrated performance of the technology are as follows:

- technology status,

- reliability and maintenance requirements,

- secondary waste streams,

- separation efficiency,

- safety and health,

- operational complexity,

- globe-box capability,

- environmental impact, and

- cost of technology.

\subsubsection{Final Waste Forms Technical Support Group}

In general terms, the Final Waste Forms TSG assumes that DOE would not immediately pursue the delisting option, and, therefore, that the waste form performance criteria would have to include compliance with the regulatory criteria for characteristic, listed, and land-banned wastes. ${ }^{8} \quad$ Among the elements this group has selected as desirable to consider are the following:

- long-term durability of the waste form in the disposal setting and

- the desired properties of final waste form

- compositional flexibility, 
- minimal volume increase, and

- low unit cost.

In terms of performance criteria, this group suggested the following elements:

- compression strength,

- resistance to thermal cycling,

- radiation stability,

- chemical durability,

- gas generation,

- biological stability,

- leach resistance,

- free liquid,

- hydraulic parameter,

- RCRA compliance,

- immersion, and

- full-scale demonstration.

The main emphasis in evaluation will consider

- whether the technology has been extensively tested on specific process components,

- whether the technology is found to be effective (high waste loadings with minor preprocessing required),

- whether a small fraction of original volume is in the secondary waste stream, and

- whether it is documented that the technology has passed the Toxicity Characteristic Leaching Procedure (TCLP). 
In addition this group has defined its data base of processes considering

- capabilities,

- versatility, and

- developmental status.

\subsubsection{Waste Destruction and Stabilization Technical Support Gioup'}

The Waste Destruction and Sabilization Technical Support Group group acknowledges that DOE has established general criteria that successful treatment technologies must achieve for social and political acceptability." The technologies must be cost-effective, and final waste forms must meet or exceed all applicable DOE, U. S. Environmental Protection Agency (EPA), and state regulatory requirements. In the opinion of this group, some technology developers lose sight of items like

- manufacturability.

- cost containment.

- operability,

- materials of construction, and

- market for technology.

The group suggests that the technologies must be able to conform to minimum performance requirements. Items making up this ability are as follows:

- Waste acceptance criteria

What are the feed compositions and forms that can be accepted by this process, and what fraction of the total mixed waste stream does this represent?

- Process effectiveness

How well does the technology perform, and what are the anticipated advantages over existing alternatives? 
- Secondary waste

What are the nature and quantity of any secondary waste?

- Off-gas composition

What are the nature and quantity of off-gas produced by the primary technology?

- ALARA concems

These concerns include the reliability and maintainability of the technology while treating potentially highly radioactive and toxic waste streams.

Consequently, the technology should minimize buildup of hazardous materials in the process. It must require minimum personnel. It must be adaptable to remote operation in the case of penetratıng radiation and treatment of alpha-contaminated wastes.

- Permitability

This is a time-consuming and costly process; pursuit of an alternate technology that may offer regulatory and public acceptance advantages in addition to technical advantages is justified.

- Risk assessment

Analysis will determine the risks associated with implementing and operating facilities incorporating a given technology

- Cost Benefit analysis

A life-cycle cost breakdown will be performed, the depth of the analysis being dependent on the maturity of the technology development and the level of uncertainty in the key elements of the analysis

- Compatibility of an integrated process system

This will focus on the ultimate requirements to interface acceptably with front-end handling, generation of final waste forms, and second-stage destruction and off-gas treatment to form an integrated process system. 


\subsubsection{Second-Stage Destruction and Orf-Gas Treatment Technical Support Group ${ }^{10}$}

The Second-Stage Distruction and Off-Gas Treatment TSG mentioned DOE criteria for successful treatment technologies ${ }^{10}$ such as

- social acceptability;

- political acceptability;

- cost-effectiveness;

- final waste that is able to meet or exceed all the applicable regulatory requirements as mandated by DOE, EPA, and state agencies;

- ability to meet the requirements in the Federal Facility Compliance Agreements (FFCA)s; and

- time-frame remediation of $<30$ years at DOE sites.

This group mentions some criteria that the TSG members were given to evaluate technical task plans (TTPs). These may also apply as general selection criteria:

- Versatility

Can the technology accept a wide range of influent characteristics?

- Permitability

Can the technology be permitted and can NEPA documentation be obtained?

- Technical risk

At what level has the technology been demonstrated?

- Schedule for operation

How soon can the technology be applied to an operating system? 
In addition, other elements of interest for evaluation are

- reliability,

- component lifetime,

- maintainability,

- technology maturity,

- cost criteria,

- criteria for secondary streams, and

- criticality control in pollution-control equipment.

\subsection{CERCLA APPROACH TO DECISION MAKING"}

In response to the need for a comprehensive and consistent approach to the complex issue of mixed waste management, a generalized methodology for remediation of a mixed waste site has been developed by EPA, using requirements set forth in CERCLA as a basis. "

The CERCLA process has been compared with a formal value engineering program as implemented by the Formerly Utilized Sites Remedial Action Program, "an environmental restoration program committed to the implementation of the EPA's remedial investigation and feasibility study process." "' Activities necessary to select a process alternative are identified as (1) information (i.e., fact gathering); (2) speculation (i.e., brainstorming); (3) analysis (i.e., evaluation); (4) development (i.e., selection); and (5) recommendations (i.e., reporting).

The detailed technical evaluation proposed by CERCLA addresses performance. In particular, the aspects of effectiveness are as follows: 
Volume Reduction: Remedial alternatives should be evaluated in terms of their ability to perform the intended function, such as containment, diversion, removal, destruction, or treatment. This score assesses the ability of the system to reduce waste volume. A measurable way to express this is net output volume divided by net input volume.

Waste generation: The same principle mentioned in volume reduction applies here. Waste generation can be evaluated by the volume of waste matrix, overburden, and horizontal plume as defined in the input system requirements.

Compliance with ARARs: CERCLA proposed that the user should establish which environmental and public health standards are relevant or applicable at the site and evaluate proposed alternatives according to those standards. In evaluating alternatives, the user may institute changes that improve them. Compliance with ARARs is measured as the degree to which process-specific ARARs are satisfied.

Flexibility of design: CERCLA addresses this as follows: any special site or waste conditions that affect performance should be considered, and the design should be tailored to accommodate those conditions. The evaluation should also consider the effectiveness of combinations of technologies. This performance measure assesses the flexibility of the system or subsystems after construction. The flexibility of the system is estimated by measuring the fraction of the system consisting of replaceable COTS parts or components. This measure assumes that systems that have a high proportion of COTS parts can be modified more easily than systems that have a high proportion of custom parts.

Robustness: CERCLA addresses this issue the same way as flexibility of design in that robustness is a measure of the system's ability to accommodate unanticipated inputs without modification to the system. 
Useful life: CERCLA addresses this point because most remedial technologies, with the possible exception of destruction, deteriorate with time. Often deterioration can be slowed through proper operation and maintenance, but the technology eventually may require replacement. Each alternative should be evaluated in terms of the projected service level of its component technologies. Resource availability in the future life of the technology, as well as the appropriateness of the technology, must be considered in estimating the useful life of the project. This performance measure is intended to assess the ability of the system to remain operational throughout the remediation process. It may be measured as the ratio of the expected time until the necessary line- item and capital equipment replacement costs exceed $50 \%$ of the acquisition cost for the total remediation time.

A vailability: CERCLA addresses this as a reliability issue because evaluations of the operation and maintenance requirements of remedial alternatives should emphasize the availability of labor and materials as well as their costs. Also, the frequency and complexity of necessary operation and maintenance should be considered in evaluating the reliability of alternatives. Technologies requiring frequent or complex operation and maintenance activities should be regarded as less reliable than technologies requiring little or straightforward operation and maintenance.

Environment/public health: CERCLA addresses this as a safety issue in that each remedial alternative should be evaluated with regard to safety. This evaluation should include shortterm and long-term threats to the safety of nearby communities and environments as well as those to workers during implementation. Major risks to consider are fire, explosion, and exposure to hazardous substances due to both on-site and off-site activities during remedial action implementation. This score assesses the ability of the system to maintain a safe environment. A measurable way of expressing this is the ratio of the capital costs defined as "important-to-safety" to the life-cycle cost of the system. Labor costs are not incorporated in this measure. 
Technical risk: CERCLA addresses this as an issue of reliability and demonstrated performance; that is, the technical analysis of remedial alternatives should not be based on the presumed performance of untested methods. An estimate of the probability of failure, in either qualitative or quantitative terms, should be made for each component technology and for the complete alternative. The user should give preference to technologies that have proven effective under waste and site conditions similar to those anticipated. Technical risk is assessed as the proportion of the system that has been demonstrated under similar waste and site conditions, plus the proportion of the system that is similar to technology demonstrated under similar waste and site conditions.

Noncarcinogenic safety risk: CERCLA addresses this as a safety issue. This evaluation should include short- and long-term threats to the safety of nearby communities and environments as well as those to workers during implementation. This score assesses the ability of the system to maintain a safe environment. A measurable way of expressing this is the ratio of the hazard index with the process to the hazard index without the process.

Carcinogenic safety risk: CERCLA addresses this as a safety issue-like the issue of noncarcinogenic safety risk. This score assesses the ability of the system to maintain a safe environment. A measurable way of expressing this is the ratio of the cancer incidence with the process to the cancer incidence without the process.

System implementability: CERCLA addresses this issue as part of site conditions in "Implementability." The constructability of remedial technologies under actual site conditions is fundamental to the technical analysis of alternatives. The ability to actually build, construct, or implement the remedial technology on the site must be assessed. The demonstrability of the system is assessed by using the fraction of subelements that cannot be demonstrated before full-scale implementation. 
Conditions Extemal to the Site permits: CERCLA addresses this issue in "Implementability" in that conditions external to the site that affect the implementability of remedial technologies include the availability and acceptability of off-site disposal sites and the equipment available for construction. Certain remedial activities may require zoning clearances and local permits in addition to compliance with applicable state and federal regulations. The number of permits required to perform remediation activities is an indicator of regulatory complexity.

Off-Site Disposal: CERCLA addresses this issue in "Implementability" in that conditions external to the site that affect the implementability of remedial technologies include the availability and acceptability of off-site disposal sites and the equipment available for construction. Off-site disposal may be measured as the fraction of waste that cannot be moved to off-site disposal.

Complexity of operations-automation: CERCLA addresses this issue in "Reliability" in that evaluations of the operation and maintenance requirements of remedial alternatives should emphasize the availability of labor and materials as well as their costs. Also, the frequency and complexity of necessary operation and maintenance should be considered in evaluating reliability of alternatives. This performance measure estimates the level of automation as the ratio of operation hours to hours of labor.

Complexity of operations-training: CERCLA addresses this issue in "Reliability" in that evaluations of the operation and maintenance requirements of remedial alternatives should emphasize the availability of labor and materials as well as their costs. Also, the frequency and complexity of necessary operation and maintenance should be considered in evaluating reliability of alternatives. This performance measure is based on the mean years of specialized training required to operate the system.

Time to demonstrate: CERCLA addresses this issue in "Implementability" in that demonstration time includes the time it takes for special studies, design, construction, and any 
other technical steps that may be required for demonstration. Demonstration-time estimates should take account of precautions. The user should evaluate alternatives in terms of the most likely construction schedule, based on experience at similar sites or on a standard engineering procedure like critical path analysis. Temporal risk is measured as the critical path time from initiation of design to initial operation at demonstration.

Implementation risk: CERCLA addresses this issue in "Implementability" in that implementation time includes the time it takes for special studies, design, construction, and any other technical steps that may be required for implementation. Implementation-time estimates should take account of precautions. The user should evaluate alternatives in terms of the most likely construction schedule, based on experience at similar sites or on a standard engineering procedure like critical path analysis. This performance measure is based upon the scheduled time from evaluation of design to beginning of operations.

Life-cycle cost: CERCLA addresses this issue because evaluations of the operation and maintenance requirements of remedial alternatives should emphasize the availability of labor and materials as well as their costs. Also, the frequency and complexity of necessary operation and maintenance should be considered in evaluating the reliability of alternatives. This is a measure of the total cost of the remediation system. 


\section{DECISION METHODOLOGY RECOMMENDED IN THIS REPORT}

Several methodologies that have been postulated as viable decision tools have been presented in

Sect. 2. Several groups of criteria elements making up these and other methodologies have been presented in the last sections of Sect. 3. A CERCLA summary of selection criteria elements has also been presented in Sect. 3.2. A compilation of decision criteria elements from all these sources is illustrated in Table 1. MWIP has grouped these decision criteria into six categories: (1) criteria used to evaluate effectiveness, (2) criteria to evaluate reliability, availability, and maintainability, (3) criteria to evaluate regulatory aspects, (4) criteria to evaluate development status, (5) criteria to evaluate environment, health, and safety concerns, and (6) criteria to evaluate cost. Tables 2 to 7 illustrate these categories.

The methodology recommended here consists of three steps. First, the selection criteria elements will be determined based on the previous methodologies and opinions of the TSGs. Second, evaluation mechanism(s) will be proposed for these criteria elements so the elements can be aggregated to arrive at a numerical value for ranking purposes during the decision-making process. Third, to obtain consensus in terms of appropriate selection elements and their evaluation mechanism(s) among the interested parties, a meeting directed by a facilitator will be conducted.

\subsection{DETERMINATION OF SELECTION CRITERIA ELEMENTS}

Decision-criteria elements established in previous decision methodologies or developed by TSGs may differ on certain items. However, there is a core of elements that seems to satisfy the needs of most parties and that points towards the same type of evaluation purpose. From this group of elements, MWIP will establish the core of the decision elements. The following is the comprehensive list of criteria elements grouped under the respective categories: 


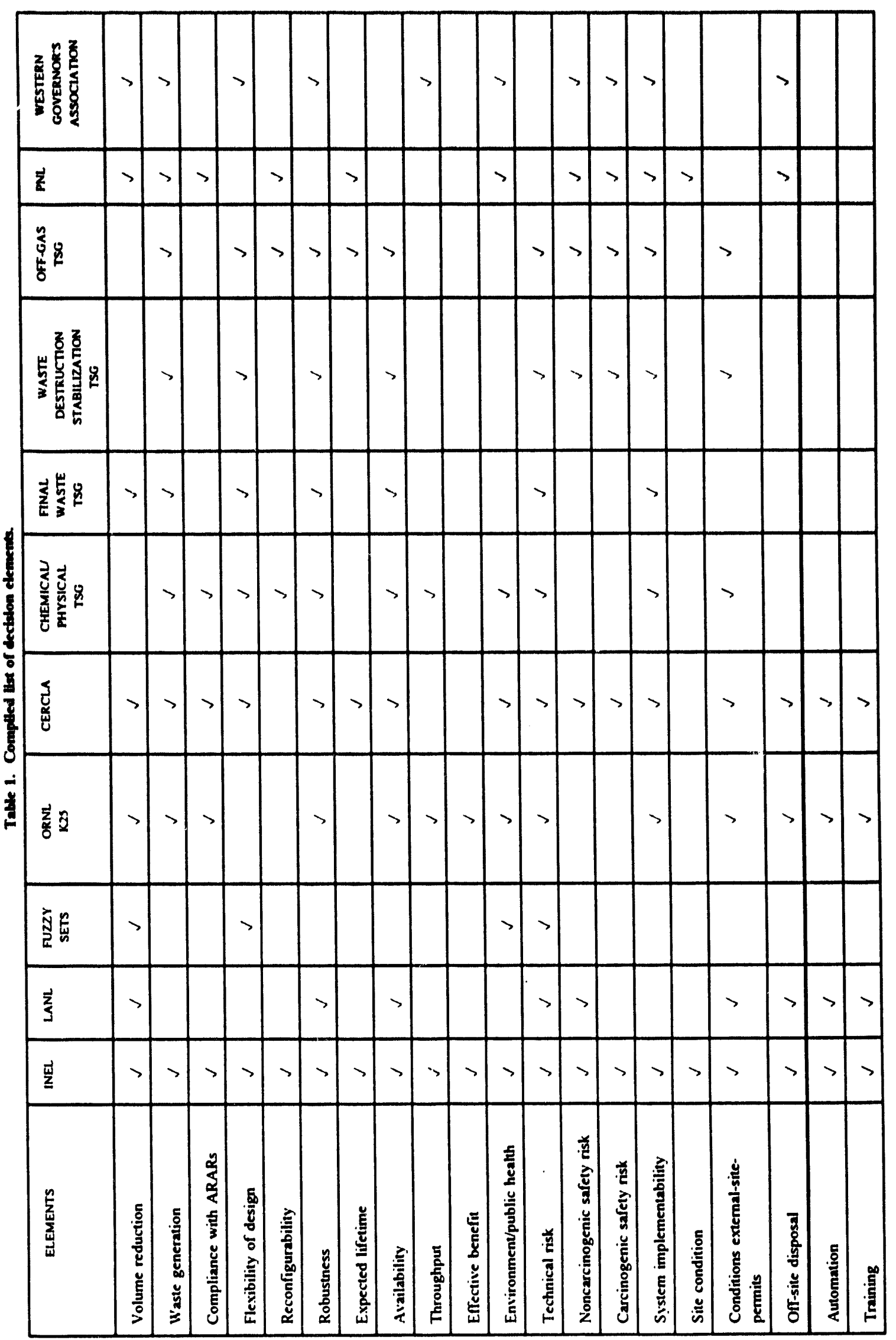


Table 1. Complited tist of dectalon elemernse (condinued)

\begin{tabular}{|c|c|c|c|c|c|c|c|c|c|c|c|}
\hline ELEMENTS & INEL & LANL & $\begin{array}{l}\text { FUZZY } \\
\text { SETS }\end{array}$ & $\begin{array}{l}\text { ORNL } \\
\text { K2S }\end{array}$ & CERCLA & $\begin{array}{l}\text { CHEMACAL } \\
\text { PHYSICAL } \\
\text { TSO }\end{array}$ & $\begin{array}{l}\text { FINAL } \\
\text { WASTE } \\
\text { TSG }\end{array}$ & $\begin{array}{l}\text { WASTE } \\
\text { DESTRUCTION } \\
\text { STABRLZATION } \\
\text { TSG }\end{array}$ & $\begin{array}{c}\text { OFF-GAS } \\
\text { TSG }\end{array}$ & me & $\begin{array}{l}\text { WESTEEN } \\
\text { COVERNORS } \\
\text { ASOOCANTION }\end{array}$ \\
\hline Time to demonstrate & $\checkmark$ & & & $\checkmark$ & $\checkmark$ & $\checkmark$ & 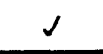 & 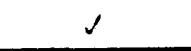 & 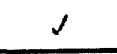 & & 2 \\
\hline Implementation risk & $\sqrt{2}$ & & & 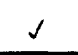 & $s$ & & $\checkmark$ & s & 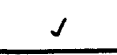 & & \\
\hline Life cycle cost & $\sqrt{2}$ & $\checkmark$ & $\sqrt{ }$ & J & $\checkmark$ & $\checkmark$ & $s$ & $\checkmark$ & $\sqrt{2}$ & $\checkmark$ & $\sqrt{2}$ \\
\hline Contamination control & & $\checkmark$ & $\sqrt{2}$ & & & 2 & & $\checkmark$ & & & \\
\hline $\begin{array}{l}\text { Destruction and removal } \\
\text { efficiency }\end{array}$ & & s & $\checkmark$ & & & $\checkmark$ & & $\checkmark$ & & $\checkmark$ & \\
\hline Final waste form & & $\checkmark$ & & & & & $\checkmark$ & & & & $\checkmark$ \\
\hline Scalability & & $\checkmark$ & & & & $\checkmark$ & & & & & \\
\hline Simplicity & & $\sqrt{2}$ & & 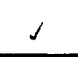 & & & & & & & $\checkmark$ \\
\hline Public acceptance & & $\sqrt{ }$ & $\checkmark$ & & & $\checkmark$ & & & & 2 & $\checkmark$ \\
\hline Regulatory compliance & & $\sqrt{ }$ & $\checkmark$ & & & $s$ & & & & $s$ & $\checkmark$ \\
\hline Maintainability & & $\sqrt{2}$ & & & & $s$ & & & $\checkmark$ & $s$ & $\checkmark$ \\
\hline Employment & & & $\checkmark$ & & & & & & & $\checkmark$ & \\
\hline Political controversy & & & $\sqrt{2}$ & & & & & & & $\checkmark$ & $\checkmark$ \\
\hline Transportation of residues & & & 8 & & & & & & & $\checkmark$ & \\
\hline Landfill & & & $\checkmark$ & & & & & & & & \\
\hline Long-term exposure & & & $\checkmark$ & & & & & & & & \\
\hline Surieillance & & & 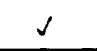 & & & & & & & & \\
\hline Waste retrieval & & & $\checkmark$ & & & & & & & & \\
\hline Risk to employees & & & $\checkmark$ & $\checkmark$ & & & & & & & 2 \\
\hline $\begin{array}{l}\text { Meet waste discharge } \\
\text { requirements }\end{array}$ & & & & & & $\checkmark$ & & $\checkmark$ & & & \\
\hline Compression strength & & & & & & & $\checkmark$ & & & & \\
\hline Resistance to thermal cycling & & & & & & & $\sqrt{2}$ & & & & \\
\hline Radiation stability & & & & & & & $\checkmark$ & & & & \\
\hline
\end{tabular}




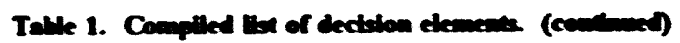

\begin{tabular}{|c|c|c|c|c|c|c|c|c|c|c|c|}
\hline ELEMENTS & nEZ & LANL & $\begin{array}{c}\text { FUZZYY } \\
\text { SETS }\end{array}$ & $\begin{array}{l}\text { ORNR } \\
\text { KCSS }\end{array}$ & CERCLA & $\begin{array}{c}\text { CHEMACAL } \\
\text { PHYSCAL } \\
\text { TSO }\end{array}$ & $\underset{\text { WASTE }}{\text { FoO }}$ & 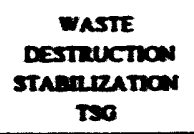 & $\underset{\text { TSC }}{\text { OFFas }}$ & $\mathbf{m e}$ & 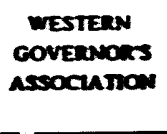 \\
\hline Chemical durability & & & & & & & $\sqrt{2}$ & & & & \\
\hline Gas generation & & & & & & & $\checkmark$ & & & & \\
\hline Biological stability & & & & & & & s & & & & \\
\hline Material of construction & & & & & & & & $s$ & & & \\
\hline Market for technology & & & & & & & & 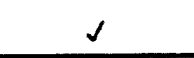 & & & \\
\hline ALARA concerns & & & & & & & & 2 & & & \\
\hline Criticality & & & & & & & & & J & & \\
\hline
\end{tabular}




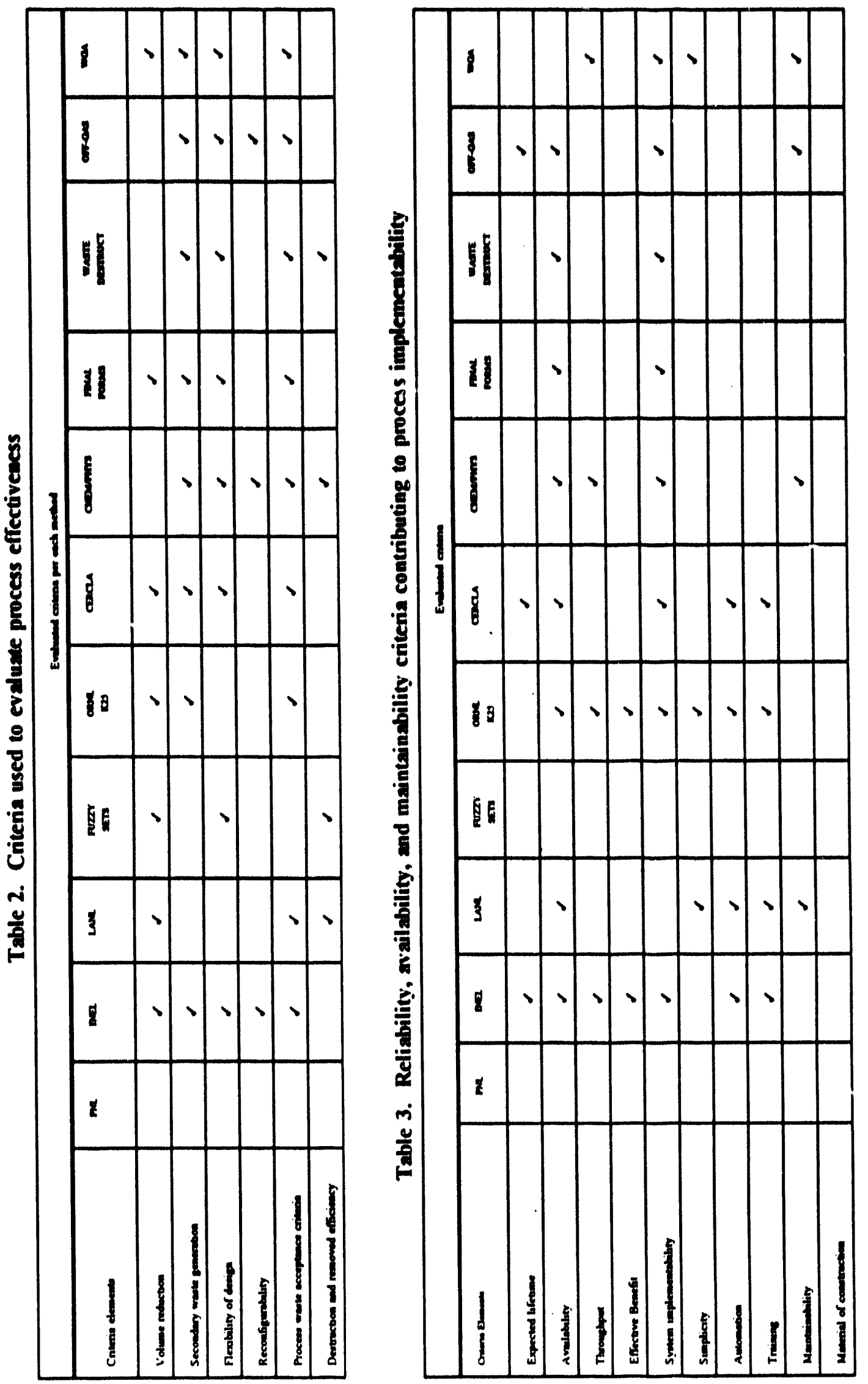


Table 4. Criteria to evalume regulatory aspects

\begin{tabular}{|c|c|c|c|c|c|c|c|c|c|c|c|}
\hline & \multicolumn{11}{|c|}{ Evaluened criveris } \\
\hline Crnerse denestos & PNL & INEL & LANL & $\begin{array}{c}\text { ruzZr } \\
\text { SETS }\end{array}$ & $\underset{K 23}{\text { ORNL }}$ & CERCLA & CHENemYYs & $\begin{array}{c}\text { monel } \\
\text { porems }\end{array}$ & $\begin{array}{c}\text { WASTE } \\
\text { DESTRUCT }\end{array}$ & OFF-Gas & man \\
\hline $\begin{array}{l}\text { Environment' } \\
\text { public health }\end{array}$ & & $\therefore$ & & $\checkmark$ & ' & $\checkmark$ & $\checkmark$ & & & & ${ }^{\prime}$ \\
\hline Site conditions & & $\checkmark$ & & & & & & & & & \\
\hline $\begin{array}{l}\text { Exernal condinions } \\
\text { sine permins }\end{array}$ & & & & & & & & & & & s \\
\hline Off-Sire disposal & & $\checkmark$ & $\therefore$ & & $\therefore$ & $J$ & & & & & 1 \\
\hline Public acceptence & & & $\therefore$ & $\checkmark$ & & & $s$ & & & & 1 \\
\hline Regulatony compliance & & & $\therefore$ & 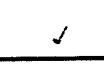 & & & 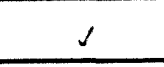 & & & & \\
\hline Aleet discharge limins & & & & & & & $\therefore$ & & $s$ & & \\
\hline ALARA concerms & & & & & & & & & $\vdots$ & & \\
\hline Criticality: & & & & & & & & & & & \\
\hline
\end{tabular}

Table 5. Evaluation of the development status of a emerging technology

\begin{tabular}{|c|c|c|c|c|c|c|c|c|c|c|c|}
\hline & \multicolumn{11}{|c|}{ Evaluabed Criveria } \\
\hline Crineris elements & PNL & INEL & LANL & $\begin{array}{c}\text { FUZZY } \\
\text { SETS }\end{array}$ & $\begin{array}{c}\text { ORNL } \\
\text { K2S }\end{array}$ & CERCLA & CHEMPHYS & $\begin{array}{c}\text { FINAL } \\
\text { FORAIS }\end{array}$ & $\begin{array}{c}\text { WASTE } \\
\text { DESTRUCT }\end{array}$ & OFF-GAS & WGA \\
\hline Tecthnical risk & & $s$ & 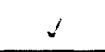 & 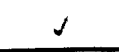 & $\checkmark$ & $J$ & $s$ & 1 & $J$ & $J$ & \\
\hline Time to demonstrate & & $\checkmark$ & & & 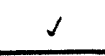 & 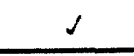 & $s$ & 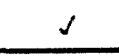 & 1 & 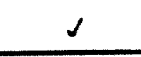 & \\
\hline Implemenemition rist & & $\checkmark$ & & & 2 & 1 & & $\checkmark$ & $\checkmark$ & 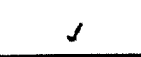 & \\
\hline Scalebility & & & J & & & & $s$ & & & & \\
\hline
\end{tabular}




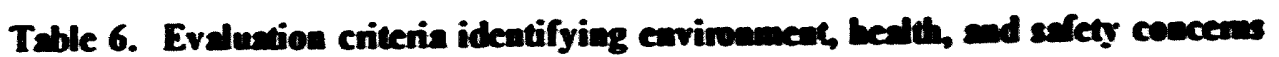

\begin{tabular}{|c|c|c|c|c|c|c|c|c|c|c|c|}
\hline \multirow[b]{2}{*}{ Criveria elements } & \multicolumn{11}{|c|}{ Evalumed crineria } \\
\hline & PNL & NEL & LANR & $\begin{array}{l}\text { FUZZY } \\
\text { SETS }\end{array}$ & $\begin{array}{c}\text { ORNR } \\
\text { K25 }\end{array}$ & cencen & cheMrtrys & $\begin{array}{l}\text { FanNe } \\
\text { FOasus }\end{array}$ & $\begin{array}{c}\text { WASTE } \\
\text { DESTIUCT }\end{array}$ & Orf-ons & $\operatorname{man}$ \\
\hline Noacancinogenic salety rist & & 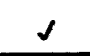 & J & & & 7 & & & 1 & 1 & \\
\hline Carcinogenic sufety rist & & $\checkmark$ & & & & $s$ & & & 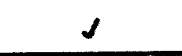 & 1 & s \\
\hline Contumination control & & & J & 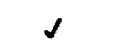 & & & 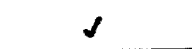 & & 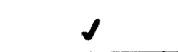 & & \\
\hline
\end{tabular}

Table 7. Criteria used to evaluane process cost

\begin{tabular}{|c|c|c|c|c|c|c|c|c|c|c|c|}
\hline \multicolumn{12}{|c|}{ Evalumed criverin } \\
\hline Criveris elements & NEL & LAML & $\begin{array}{c}\text { FUZZY } \\
\text { SETS }\end{array}$ & $\begin{array}{c}\text { ORNL } \\
\text { K2S }\end{array}$ & PNL & WGA & CERCLA & $\begin{array}{l}\text { CHENW } \\
\text { rrYS }\end{array}$ & $\begin{array}{l}\text { FDNAL } \\
\text { FORens }\end{array}$ & $\begin{array}{c}\text { WASTE } \\
\text { DESTRUCT }\end{array}$ & Off-GAS \\
\hline Life-cycke cost & 1 & J & 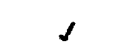 & s & $\checkmark$ & $\checkmark$ & 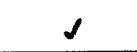 & $\sqrt{2}$ & 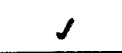 & & $j$ \\
\hline
\end{tabular}




\section{Process Effectiveness}

- volume reduction,

- waste generation,

- contamination control,

- destruction and removal efficiency,

- flexibility of design, and

- robustness.

2. Developmental Status

- development status,

- technical risk/demonstrability,

- implementation risk, and

- time to demonstrate.

3. Life-Cycle Cost

- life-cycle-cost.

4. Implementability

- system implementability, simplicity, and maintainability.

5. Regulatory

- regulatory compliance,

- public acceptance,

- conformity discharge requirements,

- conformity to LDR requirements for final waste and to conditions external to site-permits. 


\subsection{EVALUATION OF DECISION CRITERIA ELEMENTS AND AGGREGATION MECHANISM}

There are two suggested ways to evaluate the decision criteria elements. The first mechanism is based on determining numerical values for these elements from straightforward formulas. The second mechanism is based on determining figures of merit for these elements. Once the different criteria elements have been evaluated, a global number involving all these elements in an aggregated fashion must be calculated for every technology considered for selection. Evaluators may consider that one criteria element does not have the same importance or weight as other elements. Consequently, the weighting factor must be considered in the aggregation mechanism.

\subsubsection{Evaluation of Decision Citeria Elements}

The decision criteria elements are determined from previous methodologies. ${ }^{1-6}$ The formulas for evaluation are also taken from previous methodologies-as well as the figures-of-merit evaluation procedures whenever possible. The evaluation of the decision criteria elements is grouped under different categories.

1. Process Effectiveness

Volume reduction. This score assesses the ability of the system to reduce waste volume. A measurable way of expressing this is net output volume divided by net input volume. The evaluation is based on calculated numerical values as follows:

$$
E_{1}=1-V_{0} / V_{1}
$$

where

$V_{0}^{\prime} \quad=$ volume of output material from the process, and

$V_{1}=$ volume of waste matrix. 
The evaluation is based on these figures-of-merit values:

$$
\begin{aligned}
& E_{1}=0.8 \text { if above-average reduction of waste volume, } \\
& E_{1}=0.5 \text { if an average reduction of waste volume, } \\
& E_{1}=0.2 \text { if below-average reduction of waste volume, and } \\
& E_{1}=0.0 \text { if the system increases the volume of waste. }
\end{aligned}
$$

Waste generation. This scores the ability of the system to minimize waste generation. A measurable way of expressing this is the ratio of the volume of contaminated process material to the volume of input. The evaluation is based on calculated numerical values as follows:

$$
E_{2}=1-V_{0} / V_{i},
$$

where

$$
\begin{aligned}
& V_{0}=\text { volume of output material from the process, and } \\
& V_{1}=\text { volume of waste matrix. }
\end{aligned}
$$

The evaluation is based on these figures-of-merit values:

$$
\begin{aligned}
& E_{2}=0.8 \text { if above-average reduction of waste volume, } \\
& E_{2}=0.5 \text { if an average waste generation, } \\
& E_{2}=0.2 \text { if above-average waste generation, and } \\
& E_{2}=0.0 \text { if the system increases the waste generation. }
\end{aligned}
$$

Contamination Control. This criterion assesses the ability of a technology to control the spread of radioactive and hazardous contaminants. The evaluation is based on figure-of-merit values; the scores for this parameter start with a value of $E_{3}=0.8$ and subtract as follows:

0.2 if there is particulate carryover,

0.2 if there is metal volatilization $\left(>2000^{\circ} \mathrm{F}\right)$, 
0.2 if there is $\mathrm{NO}_{x}$ formation, and

0.2 if secondary discharge treatment is required.

Destruction and removal efficiency. This criterion assesses the ability to remove unwanted contaminants from the waste stream. The evaluation is based on calculated numerical values as follows:

$$
E_{4}=D R E \text {. }
$$

The evaluation is based on these figures-of-merit values:

$E_{4}=1.0$ if all contaminants are likely removed to regulation standards,

$E_{4}=0.5$ if only target contaminants are removed to regulation standards, and

$E_{4}=0.0$ if additional treatment is required to meet regulation standards.

Flexibility of design. This scores assesses the flexibility of the system or subsystems after construction. The evaluation is based on calculated numerical values as follows:

$$
E_{5}=F_{s} / F t \text {, }
$$

where

$$
\begin{aligned}
F_{s}= & \text { number of functional subelements within a configuration option whose } \\
& \text { requirements are satisfied with COTs, and } \\
F_{t}= & \text { total number of functional subelements in the configuration option. }
\end{aligned}
$$

The evaluation is based on these figures-of-merit values:

$$
\begin{aligned}
& E_{5}=0.8 \text { if above-average functional subelements, } \\
& E_{5}=0.5 \text { if an average functional subelements, } \\
& E_{5}=0.2 \text { if below-average functional subelements, and } \\
& E_{5}=0.0 \text { if no functional subelements. }
\end{aligned}
$$


Robustness. This is a measure of the system's ability to accommodate unanticipated inputs without modification to the system (off-design input). The evaluation is based on calculated numerical values as follows:

$$
E_{6}=N O S / N_{\max },
$$

where

$$
\begin{aligned}
\text { NOS = } & \text { number of predefined out-of-scope inputs as defined in the input system } \\
& \text { requirements that the system can remediate, } \\
N_{\max }= & \text { number of predefined out-of-scope inputs defined in the input system } \\
& \text { requirements. }
\end{aligned}
$$

The evaluation is based on these figures-of-merit values:

$$
\begin{aligned}
& E_{6}=0.8 \text { if above-average predefined out of scope as off-design, } \\
& E_{6}=0.5 \text { if an average predefined out of scope as off-design, } \\
& E_{6}=0.2 \text { if below-average predefined out of scope as off-design, and } \\
& E_{6}=0.0 \text { if no predefined out of scope as off-design. }
\end{aligned}
$$

\section{Developmental status}

Development status. This criterion assesses the maturity and commercial availability of a technology. Fully developed, operational, time-proven, and commercially available technologies present less technical and implementation risk than emerging, unproved technologies. The evaluation is based on calculated numerical values as follows:

$$
E_{7}=F S_{\text {tessed }} / F S_{\text {toval }} \text {, }
$$

where

$$
\begin{aligned}
F S_{\text {lessed }}= & \text { the number of subelements that have been tested under similar site and } \\
& \text { waste conditions, and }
\end{aligned}
$$


$F S_{\text {total }}=$ the number of functional subelements in the technology configuration.

The evaluation is based on these figures-of-merit values:

$E_{7}=1$ if the technology is ready to use now,

$E_{\eta}=0.8$ if the technology is fully integrated, proof-of-principle demonstrated on another waste stream,

$E_{1}=0.5$ if pilot scale demonstrated but not fully integrated,

$E_{7}=0.2$ if bench scale is being demonstrated, and

$E_{1}=0.0$ if it is in the conceptual stage.

Technical risk/demonstrability. This criterion estimates the ratio of the number of subelements demonstrated in both actual and similar environments to the total number of subelements. The evaluation based is on calculated numerical values as follows:

$$
E_{8}=\left(C_{d}+0.75 \cdot C_{s}\right) / F_{i},
$$

where

$C_{d}=$ number of demonstrated subelements,

$C_{s}=$ number of similar demonstrated subelements,

$F_{1}=$ total functional subelements.

The evaluation is based on these figures-of-merit values:

$E_{8}=0.8$ if the technology has above-average demonstrated units,

$E_{8}=0.5$ if the technology has average demonstrated units,

$E_{8}=0.2$ if the technology has below-average demonstrated units, and

$E_{8}=0.0$ if the technology has no demonstrated units. 
Implementation risk. This criterion calculates the scheduled time from approval of contract to beginning of operation. The evaluation is based on calculated numerical values as follows:

$$
E_{9}=1-T_{c} / 30 \text {, }
$$

where

$$
\begin{aligned}
& T_{c} \quad=\text { time to begin remediation after contract award, years, and } \\
& 30 \quad=\text { maximum time allowed for remediation, years. }
\end{aligned}
$$

Time to demonstrate. This parameter assesses the scheduled time from evaluation of design to beginning of operations. The evaluation is based on calculated numerical values as follows:

$$
E_{10}=1-T_{b r} / T_{\max } \text {, }
$$

where

$$
\begin{aligned}
& T_{b r} \quad=\text { time it takes to demonstrate the system, years, and } \\
& T_{\max } \quad=\text { maximum time (years) allowed for the remediation process. }
\end{aligned}
$$

\section{Life-Cycle Cost}

Life-cycle cost. This parameter assesses the cost per unit of waste remediated. The evaluation is based on calculated numerical values as follows:

$$
E_{11}=1-C_{m} / C_{\max },
$$

where

$$
\begin{aligned}
& C_{m}=\text { life-cycle cost, dollars, and } \\
& C_{\text {max }}=\text { maximum life-cycle cost of all alternatives, dollars. }
\end{aligned}
$$


The evaluation is based on these figures-of-merit values:

$$
\begin{aligned}
& E_{11}=0.8 \text { if the system probably has below-average life-cycle unit costs, } \\
& E_{11}=0.5 \text { if the system probably has average life-cycle unit costs, and } \\
& E_{11}=0.2 \text { if the system probably has above-average life-cycle unit costs. }
\end{aligned}
$$

\section{Implementability}

Simplicity. This criterion assesses the simplicity of the system. The evaluation is based on calculated numerical values as follows:

$$
E_{12}=\left(U_{\max }-U\right) /\left(U_{\max }-U_{\min }\right),
$$

where

$U_{\text {max }}=$ maximum number of unit operation encountered,

$U_{\min }=$ minimum of unit operations encountered, and

$U \quad=$ the number of unit operations in the current operations.

The evaluation is based on these figures-of-merit values:

$E_{12}=0.8$ if below-average number of unit operations

$E_{12}=0.5$ if average or normal number of unit operations, and

$E_{12}=0.2$ if above-average number of unit operations.

Maintainability. This criterion assesses the man-hours required to maintain the system. The evaluation is based on calculated numerical values as follows:

$$
E_{13}=\left(M H_{\max }-M H\right) /\left(M H_{\max }-M H_{\min }\right),
$$


where

$$
M H=\sum_{i=1}^{n}\left(T_{i} R_{i}\right),
$$

where

$$
\begin{aligned}
& n=\text { the number of parts in the system, } \\
& T_{1}=\text { the man-hours required to repair or maintain part } i, \text { and } \\
& R_{1}=\text { the reliability of part } i \text { (which is a sum of scheduled and estimated } \\
& \text { unanticipated maintenance events). }
\end{aligned}
$$

The evaluation is based on figures-of-merit values for $E_{13}$, with deductions from 1 made as follows:

0.3 if above-normal number of moving parts,

0.3 if components are difficult to access,

0.3 if questionable component reliability, and

0.2 if difficult to maintain in an alpha cell.

\section{Regulatory}

Regulatory compliance. This criterion assesses the degree to which process-specific regulations (federal, state, local, etc.) are satisfied. The evaluation is based on calculated numerical values as follows:

$$
E_{14}=F \text {, }
$$

where

$$
F \quad=\text { the fraction of all applicable regulations that are satisfied. }
$$


The evaluation is based on these figures-of-merit values:

$$
\begin{aligned}
E_{14}= & 1.0 \text { if all applicable regulations are satisfied, } \\
E_{14}= & 0.8 \text { if additional design or development will satisfy all regulations, and } \\
E_{14}= & 0.0 \text { if one or more regulations will remain unsatisfied or if additional } \\
& \text { technologies will have to be applied. }
\end{aligned}
$$

Public acceptance. This criterion assesses the local public's relative acceptance of (or opposition to) the technology. The evaluation is based on these figures-of-merit values for $E_{l s}$ :

$E_{15}=0.8$ if all effluent is captured and transported elsewhere,

$E_{15}=0.6$ if physical treatments are used,

$E_{15}=0.4$ if chemical and biochemical treatments are used, and

$E_{15}=0.2$ if thermal treatments and incineration are used.

Meet discharge requirements. The evaluation is based on these figures-of-merit values:

$E_{16}=0.8$ if the technology meets above-average discharge requirements,

$E_{16}=0.5$ if the technology meets average discharge requirements, and

$E_{16}=0.0$ if the technology meets below-average discharge requirements.

Meet LDR requirements final waste. The evaluation is based on these figures-of-merit values:

$E_{17}=0.8$ if the technology meets above-average LDR Requirements for Final Waste,

$E_{17}=0.5$ if the technology meets average LDR Requirements for Final Waste, and

$E_{17}=0.0$ if the technology meets below average LDR Requirements for Final Waste. 
Conditions extemal to site-permits. This score assesses the number of permits required to perform remediation activities. The evaluation is based on calculated numerical values as follows:

$$
E_{18}=1 / N_{p}
$$

where

$$
N_{p}=\text { estimated gross number of permits required to perform remediation. }
$$

The evaluation is based on figures-of-merit values as follows:

$E_{18}=0.8$ if the system probably requires a below-average permitting effort,

$E_{18}=0.5$ if the system probably requires an average permitting effort, and

$E_{18}=0.2$ if the system probably requires an above-average permitting effort.

\subsubsection{Evaluation of Decision-Criteria-Elements Aggregation Mechanism}

Evaluators may conclude that all items comprising the list of selection criteria elements are not equally important for the global result. This signifies that every criteria element must be weighted separately and then aggregated with the other elements in order to arrive at a number that indicates a rank among the chosen technologies.

If $w$, represents the weighting factor assigned by the evaluator(s) to the criteria element, the global ranking figure for that technology may be given by

$$
R^{(k)}=\sum w_{i} \cdot E_{i}^{(k)}
$$

where

$$
\begin{aligned}
& R^{(k)}=\text { global ranking figure for alternative } k \\
& k \quad=\text { technology alternative, } \\
& i \quad=\text { selection criteria element }
\end{aligned}
$$


$w_{1}=$ weighting factor for selection criteria element (some fuzziness may be considered in this factor upon consensus exercise), and

$E_{1} \quad=$ evaluation of criteria element.

The ranking mechanism will simply order the $R^{(k)}$ numbers in decreasing magnitude, thus indicating the ranking hierarchy among the selected technologies.

\subsubsection{Mechanism To Obtain Consensus on Criteria Elements, Evaluation, and Aggregation Mechanism}

At this point the criteria elements as well as an evaluation and aggregation mechanism have been suggested. As mentioned earlier, a compilation of previous experience in technology selection procedures has been prepared, and the results have formed the basis for this selection methodology. MWIP must reach a consensus concerning this information so that the mechanism can be applied for mixed waste technology selection without biases in the outcome. A simple mechanism consisting of three action items is suggested to reach some consensus.

Experts in the mixed waste field including engineers, technicians, environmentalists, administrative personnel, and others will participate in a meeting conducted by a facilitator. The first action item of this meeting will be to reach a consensus for the selection criteria elements. The basis has been developed in Sect. 4.3.1 and will be presented as a package to the group. The facilitator will try to gain consensus concerning the list by proceeding item by item. Among the possible outcomes of this meeting is the addition of other elements to the list.

The second action item of this meeting will be to assign weighting factors to the criteria elements. It is not expected that the moderator will gain consensus in this matter. However, the information will be handled with elements of fuzzy logic that will eventually describe the band of acceptability of the technology rather than fixed deterministic values once the evaluation is performed. 
The third action item of this meeting will be to discuss the evaluation formulas or the figures of merit assigned to each criteria element. Acceptability of these formulas or figures of merit is crucial to conduct a less controversial decision process. 


\section{ANALYSIS AND CONCLUSIONS}

The methodologies analyzed in Sects. 2 and 3 differ slightly in their application purpose. The INEL methodology was developed based on the mission of the INEL BWID systems analysis. The mission identifies and evaluates systems for the cradle-to-grave remediation of TRUcontaminated waste pits and trenches located within the SDA of INEL's RWMC. The methodology developed by INEL provides a formalized selection process wherein technologies and systems are rated and assessments are made based on performance measures and regulatory and technical requirements. The results are auditable and can be validated with field data.

LANL has developed a multiattribute technology evaluation methodology to be considered for DOE programs such as MWIP or MWTP. LANL's multiattribute technology evaluation defines two methodologies: prescreening and postevaluation methodologies.

Fuzzy-set methodologies in multicriteria analysis were developed to satisfy a need for multiatribute decision making process for the selection of treatment technologies in hazardous materials waste management. The methodology has been published and applied to a problem of technology selection for treating waste produced at a pesticide company.

ORNL criteria for assessing process tech.blogy options was developed in response to the need for a comprehensive and consistent approach to the complex issue of mixed waste management. The methodology is based on requirements set forth in CERCLA and RCRA and incorporates "lessons learned" from process design, remediation methodologies, and remediation projects. The methodology was applied to the treatment of 32,000 drums of mixed waste sludge at the Oak Ridge K-25 Site. 
The MOU between federal agencies and the Western Governors' Association is to establish a more cooperative approach to the development of technical solutions to the environmental restoration and waste management problems shared by the states, commercial entities, and the federal government. To carry out the MOU, a federal advisory group known as the DOIT committee was formed. A critical element in achieving the goals of the DOIT Initiative is developing criteria to facilitate site selection and technologies. Because selection decisions are fundamental to the success of the initiative, the general working group developing the selection criteria represents a cross section of industry, public interest groups, and federal and state representatives. These criteria and other requirements in the Stakeholder Involvements Plan will be used to request and evaluate proposals for cooperative demonstrations.

PNL has developed Phase I of a three-phased study to support evaluation of new clean up technologies for federal facilities. It directly supports the VOC-Arid Site Integrated Demonstration being conducted at the Hanford site. The purpose of the activity, which is sponsored and directed by the DOE's OTD is to develop and demonstrate new technologies for cleaning up carbon tetrachloride and other VOCs in soils and groundwater. The ultimate deployability of those innovative technologies will be the measure of their success.

In addition, the MWIP TSGs elaborated a set of criteria that aid in the selection process. Slight variations are observed in the many methodologies developed by different groups, but most of the analyzed methodologies address similar aspects in its majority. These common aspects were the core of the methodology suggested for use within MWIP for the selection of technologies. The set of criteria compiled and developed for this report have been grouped in five categories: (1) process effectiveness, (2) developmental status, (3) life-cycle cost, (4) implementability, and (5) regulatory compliance.

It has been suggested in meetings involving MWIP and EM-30 that the decision methodology be applied in two phases. The first phase must involve primarily technical aspects such as the ones included in the categories process effectiveness, developmental status, life cycle costs, and 
implementability. In addition, the phase should include some elements from the regulatory category such as regulatory compliance, meet discharge requirements, and meet LDR requirements final waste. Phase one of the methodology must act as a first screening method for selecting treatment processes. Once the first screen delivers a set of treatment technologies based on technical issues, then one can apply the second phase that includes some non-technical issues such as public acceptance, conditions external to site-permits, and others. This general procedure will simplify the selection methodology because technical issues are simpler to evaluate. Once the number of viable technologies have been narrowed, then one can apply the second phase with nontechnical elements that are normally more difficult to evaluate for each technology.

As stated earlier, this methodology has to be approved by DOE-Headquarters for its deployment. This report will be submitted to DOE-HQ for its analysis and implementation. Changes suggested from this review process will be incorporated in the methodology. 


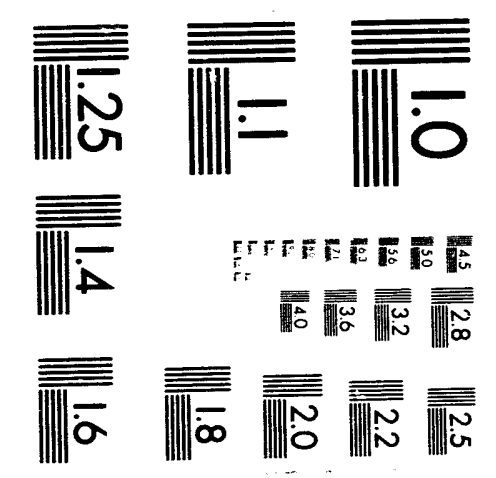




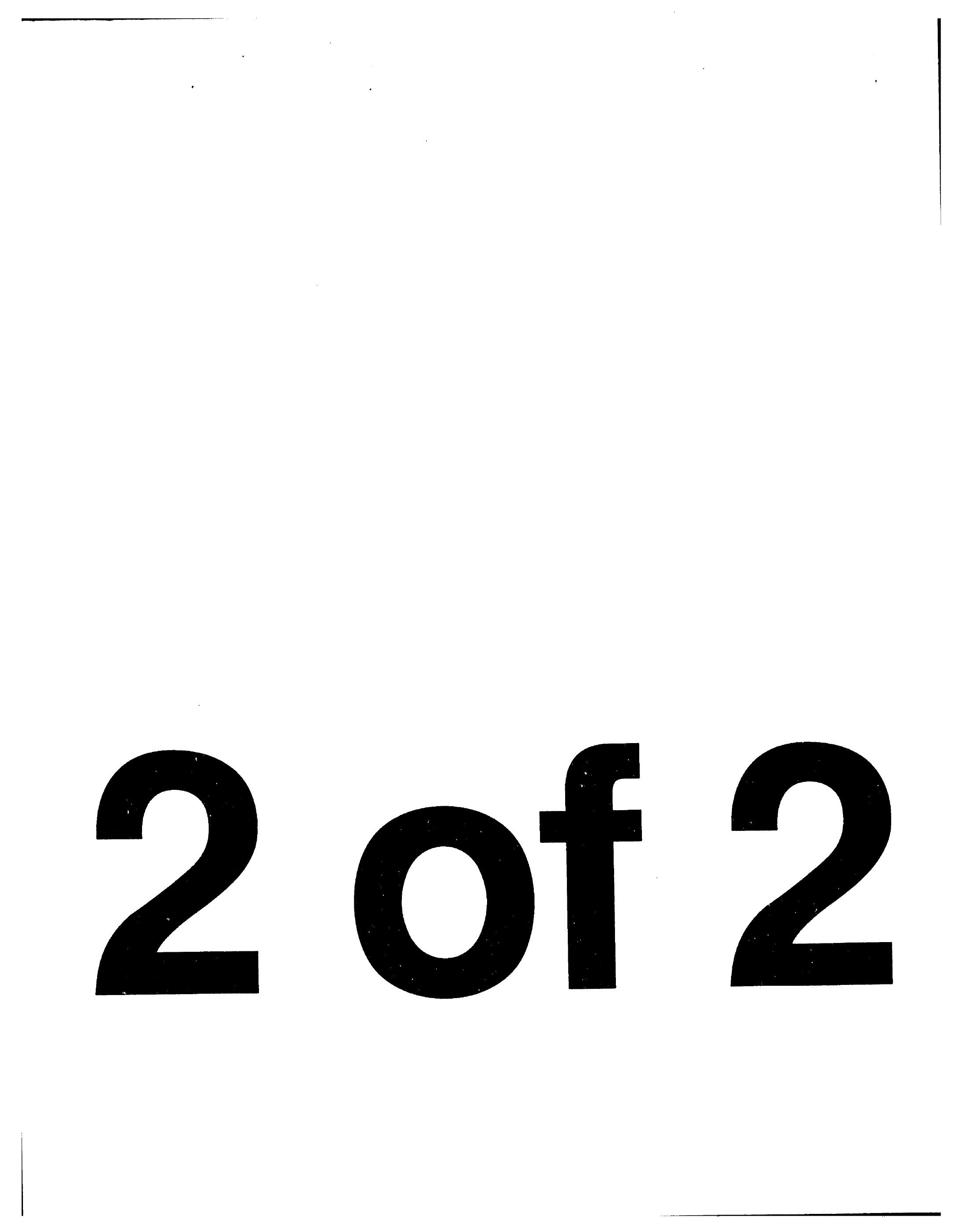




\section{REFERENCES}

I. M. C. O'Brien, J. L. Morrison, R. A. Morneau, M. J. Rudin, and F. G. Richardson, Performance-Based Technology Selection Filter Description Report. INEL Buried Waste Integrated Demonstration System Analysis Project, EGG-WTD-9989, May 1992.

2. R. B. Kidman, Multi-A ttribute Technology Evaluation, Draft report, Los Alamos National Laboratory, December 1992.

3. J. J. Ferrada, Hazardous Chemical Waste Management, Garland Publishing, Inc., New York, 1990.

4. J. B. Berry, Methodologies to Remediate a Mixed-Waste Site, M.S. degree thesis, The University of Tennessee, Knoxville, May 1992.

5. Western Governors' Association, remarks from General Ad Hoc Criteria working Group. Draft letter, 1993.

6. G. H. McCabe, Phase I Involvement for Potential Stakeholders of the VOC-A rid Integrated Demonstration. PNL-8548, BHARC-800/93/004, Battelle Seattle Research Center, December 1992.

7. C. H. Brown, Jr., and W. E. Schwinkendorf, Technical Area Status Report for Chemical/Physical Treatment, Volume I. Mixed Waste Integrated Program, Office of Technology Development, U.S. Department of Energy, Oak Ridge National Laboratory, Oak Ridge, Tennessee, May 1993. 
8. J. Mayberry, L. M. DeWitt, R. Darnell, R. Van Konynemburg, W. Greenhalg, R. Singh, P. Erickson, and R. Nakaoka. Technical A rea Status Report for Low-Level Mixed Waste Final Waste Form, Volume I Draft. Mixed Waste Integrated Program, Office of Technology Development, U.S. Department of Energy, Idaho Falls, Idaho, December 1992.

9. J. D. Dalton, R. L. Gillins, T. L. Harris, J. S. Vavruska, L. Bourduin, O. Kruger, and W. H. McCulla. Technical A rea Status Report for Waste Destruction and Stabilization, Draft. Mixed Waste Integrated Program, Office of Technology Development, U.S. Department of Energy, Idaho Falls, Idaho, February 1993.

10. N. Bergan French, J. D. Dalton, and T. L. Harris. Technical A rea Status Report for Second-Stage Destruction and Off-Gas Treatment, Draft. Mixed Waste Integrated Program, Office of Technology Development, U.S. Department of Energy, Livermore, California, September 1992.

11. U. S. Environmental Protection Agency, Guidance on Feasibility Studies Under CERCLA, EPA/540/G-85/003, Cincinnati, Ohio, June 1985. 

1. T. J. Abraham
2. P. M. Backus
3. M. Baker
4. J. M. Begovich
5-9. J. B. Berry
10. G. Bloom
11. C. H. Brown
12. A. G. Croff
13. T. B. Conley
14-20. J. J. Ferrada
21. R. K. Genung
22. J. R. Hightower, Jr.
23. D. Hutchins
24. G. Kamp
25. A. P. Malinauskas
26. L. J. Mezga
27. J. J. Perona
28. S. M. Robinson
29. M. Savage
30. R. W. Sharpe
31. P. A. Taylor
32. Central Research Library
33. Document Reference Center
34. ORNL Patent Section
35-36. ORNL Laboratory Records
37. ORNL Laboratory Records, RC

\section{EXTERNAL DISTRIBUTION}

38. N. Askew, Westinghouse Savannah River Co., P.O. Box 616, Aiken, SC 29802

39. C. Baldwin, EG\&G Rocky Flats, P.O. Box 464, Highway 93 \& Cactus, Bldg. 881, Golden, CO., 80402-0464

40. M. Ballestri, BDM Federal, 2025I Century Blvd., 4th Floor, Germantown, MD., 20874

41. J. Bassi, EM-351, U.S. Department of Energy, 12850 Middlebrook Road, Germantown, MD., 20874

42. J. Batdorf, SAIC, 545 Shoup Ave., P.O. Box 50697, Idaho Falls, ID., 83405-0697 
43. S. Bates, EG\&G Idaho, Inc., P.O. Box 1625, MS-3930, Idaho Falls, ID $83415-$ 3930

44. T. Bergsman, Battelle Pacific Northwest Laboratory, Battelle Boulevard, MS P7-41, Richland, WA 99352

45. L. Borduin, Los Alamos National Laboratory, One Bikini Road, MS K557, Los Alamos, NM 87545

46. M. Brooks, Waste Policy Institute, 555 Quince Orchard Blvd., Suite 600, Gaithersburg, MD 20879

47. H. Burns, Westinghouse Savannah River Co., P.O. Box 616, Bldg. 704-61s, Aiken, SC 29808

48. G. Bryan, Pacific Northwest Lab, Battelle, Blvd., Richland, VA 99352

49. P. Castel, U.S. DOE/HQ, WINCO, 20201 Century Blvd., Rm. 408, Germantown, MD., 20874

50. D. Chaiko, Argonne National Lab, CMT/Bldg. 205, 9700 S. Cass Ave., Argonne, IL., 60439

51. C. Collier, BDM Federal, 20251 Century Blvd., 4th Floor, Germantown, MD., 20874

52. C. Cooley, U.S. Department of Energy, EM-50, Trevion II, Washington, D.C., 20585-0002

53. T. Cooper, Westinghouse Hanford Corp., 2355 Stevens Dr., MS N3-12, Richland, WA 99352

54. A. Corstillo, FERMCO, 25 Merchant St., 3rd Floor Technology, Springdale, OH 45246

55. S. Couture, Lawrence Livermore National Lab, P.O. Box 808, L-591, Livermore, CA 94550

56. G. Coyle, EM-541, U.S. Department of Energy, 12800 Middlebrook Road. Trevion II, Germantown, MD 20874-1290

57. P. Coyle, EM-55, U.S. Department of Energy, 19901 Germantown Road, Germantown, MD 20874

58. J. Cunnane, Argonne National Lab, 9700 South Cass Ave., Bldg, 205, Argonne, IL 60439

59. J. Dalton, SAIC, 545 Shoup Ave., P.O. Box 50697, Idaho Falls, ID 83405-0697 
60. J. Dancz, SAIC, Quince Diamond Executive Center, 555 Quince Orchard Rd., Suite 500, Gaithersburg, MD 20878-4137

61. R. Darnell, EG\&G Idaho, Inc., P.O Box 1625, MS-3950, Idaho Falls, ID 834153950

62. L. Dewitt, SAIC, 545 Shoup Ave., P.O. Box 50697, Idaho Falls, ID 83405-0697

63. S. Domotor, U.S. DOE, EM-351, Trevion II, Washington, D.C. 20585

64. P. Erickson, EPA-RREL, 5995 Center Hill Ave., Cincinnati, OH 45224

65. J. Fannon, U.S. DOE, HQ/EM-50, 20201 Century Blvd., Bellmeade Bldg. II, Rm. 402, Germantown, MD 20874

66. G. Fitzgibbon, WHC, P.O. Box 1970, MS H6-07, Richland, WA 99352

67. C. Frank, EM-50, U.S. Department of Energy, Forrestal Office Building, Washington, DC 20585

68. E. Franz, Brookhaven National Lab, Environmental \& Waste Technology Center, North Railroad St., Bldg. 830, Upton, NY 11973

69. N. French, Sandia National Laboratory-Livermore, 7011 East Avenue, Livermore, CA 94550

70. M. Fuhrmann, Brookhaven National Laboratory, Building 703, Upton, NY 11973

71. A. Gatuchette, US EPA, Risk Reduction Engineering Lab, 26 W. Martin Luther King Blvd., Cincinnati, $\mathrm{OH} 45268$

72. R. Gehrke, EG\&G Idaho, Inc., 2151 N Blvd., MS-7111, P.O. Box 1625, Idaho Falls, ID 83415

73. R. Geimer, SAIC, 545 Shoup Ave., P.O. Box 50697, Idaho Falls, ID 834(05-0697

74. R. Gillins, SAIC, 545 Shoup Ave., P.O. Box 50697, Idaho Falls, ID 83405-0697

75. K. Hain, EM-55, U.S. Department of Energy, 1000 Independence Ave., SW, Washington, DC 20585

76. T. Harris, SAIC, 545 Shoup Ave., P.O. Box 50697, Idaho Falls, ID 83405-(0697

77. P. Hart, U.S. Department of Energy, EM-542, Trevion II, 19901 Germantown Rd., Germantown, MD 20874-0002

78. J. Helt, Argonne National Laboratory, 9700 S. Cass Avenue, Bldg. 205, Argonne, IL 60439

79. D. Helton, Westinghouse Savannah River Co., P.O. Box 616, Bldg. 773.41 A., Rm. 228, Aiken, SC 29802 
80. B. Hickman, Lawrence Livermore National Lab, P.O.Box 808. Livermore, CA 94550

81. D. Hjeresen, AET, MS-P641, Bikini Road, Los Alamos. NM 87545

82. J. Hunter, Westinghouse Hanford Co., P.O. Box 1970, MS L531, Bldg. 3766, Rm. 14, Richland, WA 99352

83. D. Isbell, EM-40, U.S. Department of Energy, 12800 Middlebrook Road, Trevion II, Germantown, MD 20874

84. P. Jones, BDM Federal, 2025 I Century Blvd., 4th Floor, Germantown, MD 20874

85. P. Kalb, Brookhaven National Lab, Environmental \& Waste Technology Center, North Railroad Street, Bldg. 830, Upton, NY 11973

86. T. Kan, Lawrence Livermore National Lab., P.O. Box 808, L-467. Livermore, CA 94550

87. B. Kitchen, Savannah River Laboratory, Westinghouse Savannah River Co., P.O. Box 616, Aiken, SC 29802

88. K. Kostelnik, EG\&G Idaho, Inc., P.O. Box 1625, MS-3930, Idaho Falls, ID 834153930

89. D. Kried, Battelle Pacific NW Lab, Battelle Blvd., Richland, WA 99352

90. O. Kruger, Westinghouse Hanford Company, 2355 Stevens Dr., Richland, WA 99352

91. M. Lankford, EM-552, U.S. Department of Energy, 12800 Middlebrook Road, Trevion II, Germantown, MD 20874

92. M. Larsen, SAIC, 545 Shoup Ave., P.O. Box 50697, Idaho Falls, ID 83405-0697

93. G. Leatherman, SAIC. Quince Diamond Executive Center, 555 Quince Orchard Rd., Suite 500, Gaithersburg, MD 20878-0697

94. S. Lein, EM-54, U.S. Department of Energy, 12800 Middlebrook Road, Trevion II, Germantown, MD 20874-1290

95. J. Lippold. BDM Federal, 2025! Century Blvd., 4th Floor. Germantown, MD 20874

96. P. Lurk, EM-552. U.S. Department of Energy, 12800 Middlebrook Road, Trevion II, Germantown, MD 20874

97. J. Mayberry, SAIC, P.O. Box 50697, Idaho Falls, ID 83405-0697 
98. W. McCulla, Los Alamos National Laboratory. SM 30 Warehouse, Bikini Road, MS J-563, Los Alamos, NM 87545

99. J. McFee, IT Corporation, 5301 Central Ave., NE, Albuquerque, NM 87108

100. K. Merrill, EG\&G Idaho, Inc., 2151 N Blvd., MS-3930, P.O. Box 1625, Idaho Falls, ID 83415

101. R. Moats, BDM International, 12850 Middlebrook Road, Suite 300, Germantown, MD 20874

102. J. Moore, U.S. Department of Energy, P.O. Box 2001, Oak Ridge, TN 37830-8620

103. D. Musgrave, Lawrence Livermore National Laboratory, P.O. Box 808, L-440, Livermore, CA 94550

104. T. Myrick, SAIC, P.O. Box 2501, Oak Ridge, TN 37831

105. R. Nakaoka. Los Alamos National Laboratory, P.O. Box 1663, MS-6517, Los Alamos, NM 87545

106. M. Nawar, Office of Radiation Programs, Environmental Protection Agency, 401 M St. SW, ANR-461, Washington, DC 20460

107. G. Ordaz, EM-541, U.S. Department of Energy, 12800) Middlebrook Road, Trevion II, Germantown, MD 20874

108. C. Owens, EG\&G Idaho, P.O. Box 1625, Idaho Falls, ID 83415-3960

109. R. Peters, Battelle-Pacific Northwest Lab, P.O. Box 999, MS P7-41, Richland, WA 99352

110. W. Phillips, Roy F. Weston Office of Technology Services, 12850 Middlebrook Road, Germantown, MD 20874

111. W.W. Pitt, Texas A\&M University, Department of Nuclear Engineering, College Station, TX 77843

112. B. Place, Westinghouse Hanford Co., Solids \& Liquids Waste Remediation, P.O. Box 1970, MS H5-33, Richland. WA 99352

113. W. Ross, Battelle-Pacific Northwest Lab, P.O. Box 999, MS P7-41, Richland, WA 99352

114. R. Schumacker, Westinghouse Savannah River Co., SRTC. P.O. Box 616, Bldg. 773-42A, Aiken, SC 29808

115. B. Schutte, EM-54, U.S. Department of Energy, 12800 Middlebrook Road, Trevion II, Germantown, MD 20874-1290 
116. B. Schwinkendorf, BDM Federal, 1801 Randolph Rd., SE, Argonne. IL 60439

117. G. Sevigny, Battelle-Pacific Northwest Lab, P.O. Box 999, MSIN P7-42A, Aiken, SC 29808

118. M. Shupe, EM-541, U.S. Department of Energy, Trevion II, Room 440, 19901 Germantown Road, Germantown, MD 20874-1290

119. D. Singh, Argonne National Lab, 9700 South Cass Ave., Bldg. 212, Rm. G-233, Argonne, IL 60439

120. D. Skrincosky, Strategic Technology International, 20 Avon Meadow Ln., Suite 220, Avon, CT 06001

121. S. Slate, Battelle Pacific Northwest Laboratory, 902 Battelle Blvd.. P.O. Box 999 , KI-25, Richland, WA 99352

122. S. Stein, Battelle, Seattle Research Center, 4000 NE 41st. Seattle, WA 98105 5428

123. E. Steverson, SAIC, 545 Shoup Ave., P.O. Box 50697, Idaho Falls. ID 83405-0697

124. P.Sydenticker, BDM Federal, 2025I Century Blvd., 4th Floor, Germantown, MD 20874

125. H. Turner, ARCO, 2300 W. Plano Parkway, Plano TX, 75075-8499

126. T. Timmerman, Mason \& Hanger, Bldg. 11-2, P.O. Box 50697, Idaho Falls, ID 83405-0697

127. T. Uhlmeyer, MD-Ferguson Co.. 7295 Highway 94 South, St Charles. MO 63304

128. J. Vavruska, Equinox, Ltd., 872 Don Cubero Ave., Santa Fe, NM 87501

129. C. Ward, Westinghouse Savannah River, Building 773-A, D-1134, Aiken, SC 29808

130. S. Warren, EM-442, U.S. Department of Energy, 12800 Middlebrook Road, Trevion II, Germantown, MD 20874-1290

131. J. Witzeman, P.O. Box 398704, 7400 Williey Road, Fernald. OH 45030

132. S. Wolf, U.S. Department of Energy, Trevion II. 19901 Germantown Road, Germantown, MD 20874

133. W. Wolfe, SAIC, 545 Shoup Ave., P.O. Box 50697, Idaho Falls, ID 83405-0697

134-135. Wollerman, Trevion I, 12850 Middlebrook Road, Suite 400, Room 721, Germantown, MD 20874

136. M. Zenkowich, EM-323, U.S. Department of Energy, 12800 Middlebrook Road, Germantown. MD 20874 
137. Office of Assistant Manager, Energy Research and Development, DOE-OR, P.O. Box 2001, Oak Ridge, TN, 37831

138-139. Office of Scientific and Technical Information, P.O. Box 62, Oak Ridge, TN 37831 
11
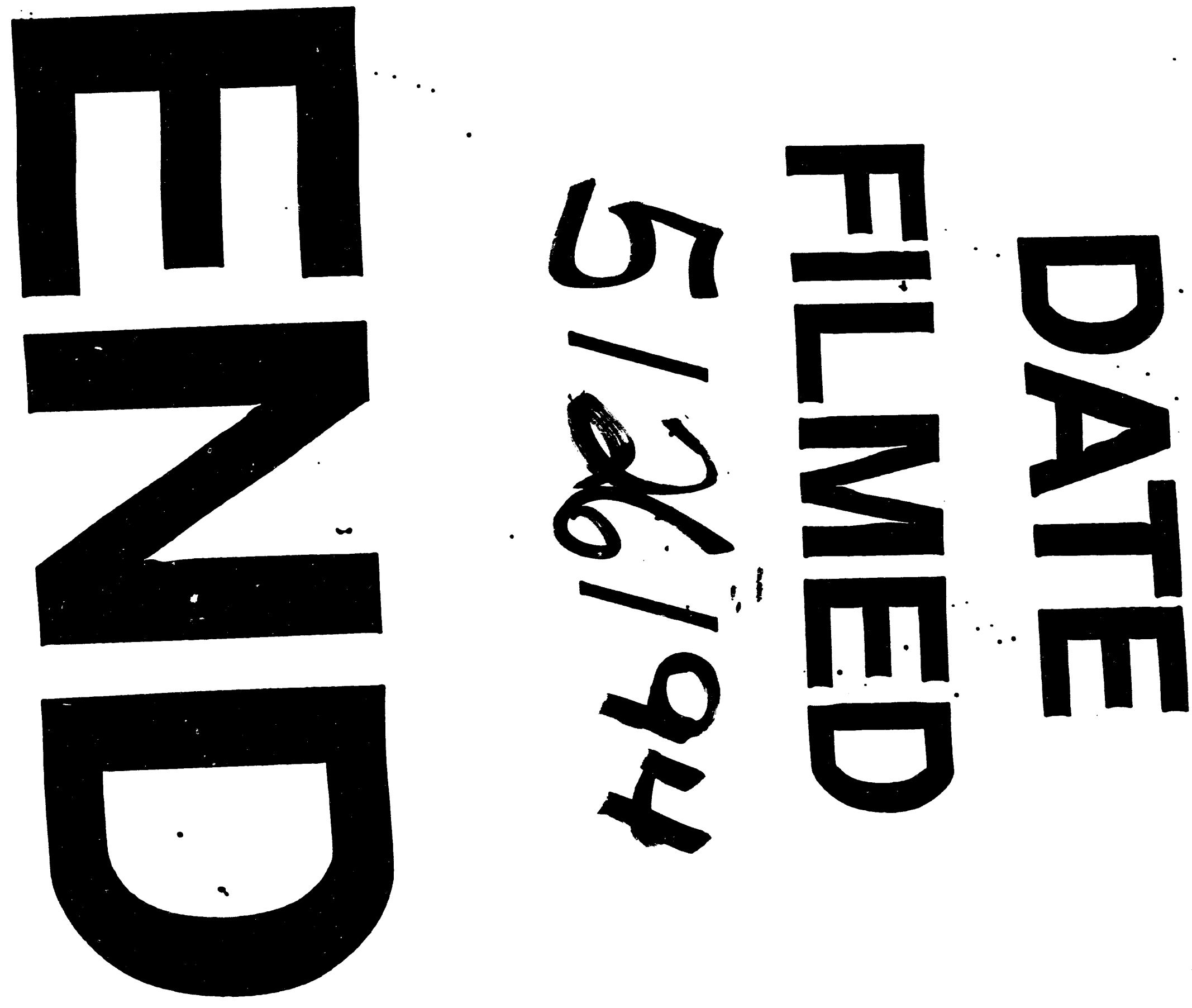


$$
\square^{-m a n}
$$

